\title{
Special Ones? The Effect of Head Coaches on Football Team Performance
}

Alex Bryson

Babatunde Buraimo

Alex Farnell

Rob Simmons

Quantitative Social Science

Working Paper No. 21-03

February 2021 


\section{Disclaimer}

Any opinions expressed here are those of the author(s) and not those of the UCL Social Research Institute. Research published in this series may include views on policy, but the institute itself takes no institutional policy positions.

QSS Workings Papers often represent preliminary work and are circulated to encourage discussion. Citation of such a paper should account for its provisional character. A revised version may be available directly from the author.

Quantitative Social Science

UCL Social Research Institute

University College London

\section{5-59 Gordon Square}

London WC1H ONU 


\title{
Special Ones? The Effect of Head Coaches on Football Team Performance
}

\author{
Alex Bryson ${ }^{1}$ \\ Babatunde Buraimo ${ }^{2}$ \\ Alex Farnell ${ }^{3}$ \\ Rob Simmons ${ }^{4}$
}

\begin{abstract}
One expects those who lead organisations to affect their performance. If not why would organisations spend so much time and money appointing and incentivising their leaders? Yet there is little evidence establishing a causal link between leaders and organisational performance. Using game-by-game linked employer-employee data for professional football in four countries over fifteen seasons we compare the performance of teams after they have sacked their Head Coach with spells where the Head Coach remains in post. We undertake a similar exercise comparing performance after a Head Coach quits with that of teams where the Head Coach remains in post. We deal with the endogeneity of Coach departures using entropy balancing to reweight teams' performance prior to the departure of a Coach so that trends in team performance prior to the departure match spells which ended with a Coach remaining in post. Consistent with theory, Head Coach quits have little or no impact on team performance whereas teams who fire their Head Coach experience small but statistically significant improvements in team performance, although this positive impact is confined to circumstances in which a team holds onto the new Coach having sacked the previous Coach. Our results lend support to the proposition that teams can benefit from Head Coach turnover, firing them when it is optimal to do so, and replacing a Head Coach during the offseason.
\end{abstract}

Keywords: managerial performance; team performance; football; entropy balancing. JEL Codes: J63, Z22

Acknowledgements: We thank seminar participants at Lancaster University, University College Cork, the University of Sheffield, the University of Minho, University College London and Reading Online Sports Economics Seminars (ROSES), the European Commission's Joint Research Centre in Milan and conference participants at the European Association of Sports Economists, Groningen, the Western Economic Association International, Portland and the Colloquium on Personnel Economics in Zurich for helpful comments. We also thank Andrew McKendrick and Vincent O'Sullivan for their comments

\footnotetext{
${ }^{1}$ UCL, IZA and NIESR

${ }^{2}$ University of Liverpool

${ }^{3}$ Lancaster University

${ }^{4}$ Lancaster University
} 


\section{Introduction}

Across a range of disciplines there is a strong prior that leaders affect performance. In military history, leaders on the battlefield are credited for victories and blamed for defeats linked to their strategies and tactics. Economists have long maintained that the person who leads an organisation can have a substantial effect on its productivity. This is because the quality of leaders' decision-making and leaders' own productivity have profound implications for the way the organization is run and thus the productivity of those further down the corporate hierarchy (Rosen, 1990). Lazear et al. (2015) confirm this to be true; an average boss adds roughly 1.75 times more to output than an average worker, with peer effects paling into economic insignificance relative to the effects of bosses.

It has, however, been very difficult to identify a causal impact of managers on performance outcomes because managers are not randomly assigned to organizations and changes in corporate leadership are usually endogenous. For this reason, some analysts have relied on unforeseen death or hospitalisation episodes to identify the effects of leaders on performance. Bennedsen et al. (2012) use hospitalization episodes to identify the effects of CEOs on corporate performance while Besley et al. (2011) use the sudden death of heads of state to establish the importance of leaders' education for growth in countries' gross domestic product.

In this paper we focus on the role of the Head Coach in determining sports teams' performance. The role of the Head Coach can vary across sports and even within a sport across countries. But in our setting of professional football, they typically have the power to recruit football players to the squad, appoint their backroom and support staff, pick the team for each game, and decide on match tactics. It seems reasonable to conjecture, therefore, that Head Coaches play a crucial role in determining team performance. Yet the literature finds little evidence of a positive performance effect following a change in Head Coach. This seems somewhat surprising since hiring is costly to firms and club owners should, in principle, have the information required to ensure a good person-job match since weekly football matches provide regular updates on the quality of potential candidates. 
Using a large, rich data set on Head Coaches from the top two tiers of four European countries over the seasons 2000/01 to 2014/15, we use entropy balancing to estimate the effects of a change in Head Coach on team performance measured as points achieved in league games played. In contrast to most of the literature, we find some positive effects of a Head Coach change following a Head Coach dismissal, though the result is sensitive to the way we define our follow up period. There is little or no performance return when a Head Coach quits. We argue that this is precisely what one would anticipate from theory. Previous studies have not been able to make this distinction between dismissals and quits or, if they have, their sample sizes have been insufficient to provide the necessary statistical power to identify Coach effects.

In Section Two, we review the literature on Head Coaches and football team performance, identifying the ways in which our paper builds on the existing literature. In Section Three we present our data and estimation techniques. Section Four presents the results before concluding in Section Five.

\section{Theory and Empirical Evidence}

In the standard model of employment relationships, workers are hired when the matchspecific surplus generated for the firm exceeds the costs of hire. Termination of the contract will occur through dismissal by the employer (often termed "layoff"), or a quit by the worker, where the value of that match for one or both parties falls below the value of an outside option (Farber, 1999). In football, club owners can update their information on Head Coach performance with the results from each game, which tend to happen on average once a week during the football season. This provides them with an opportunity to consider Head Coach performance relative to expectations on an almost continual basis, something that is harder to do in most firms where principals only receive reports of executive performance in the annual financial accounts, while monitoring executive performance may prove costly. Football club owners act on this information: Bryson et al. (2020) find that dismissals accounted for over 70 per cent of all Head Coach departures and that the gap between team performance and expected performance (captured by betting odds) is a strong predictor of dismissals. 
For the football club, the outside option is an alternative Head Coach. If Head Coaches are heterogeneous in ability then teams should be able to replace a departing Coach with a better one. Muehlheusser et al. (2016) confirm that there is substantial heterogeneity in Head Coach ability in the German "Bundesliga" and that team performance varies according to the ability of the in-coming Coach. However, there are a number of reasons why owners may be unable to improve team performance through the recruitment of a new Coach. First, while Head Coaches are heterogeneous in ability it will be difficult for club owners to identify which are the more talented among them. Their past performance may be attributable to factors other than ability, including luck, so it is not possible to read off Coach talent directly from the performance of clubs they have managed. Second, teams may be constrained in the talent they can attract. Theory suggests inefficient hiring in talent markets whereby mediocre workers are re-hired in the face of risk associated with appraising the talent of workers that are new to an industry (Tervio, 2009). This market failure arises where talent is industry-specific, is only revealed on the job and, once revealed, becomes public information. More productive firms hire those revealed to be high-ability whereas less productive firms must experiment with untested new workers. Where there is insufficient discovery of new talent firms tend to re-hire some workers known to be mediocre. Peeters et al. (2016) confirm that this market failure exists among Head Coaches in professional football in England. Third, it is uncertain a priori just how much of the "talent" Head Coaches possess is generalisable and how much is team-specific. If there is a large job-match specific component, performing well in one setting may not translate to good performance in a new setting.

For the Head Coach, the outside option comes in the form of alternative employment. Clubs searching for a new Head Coach have three possible options: recruit from the pool of unattached Coaches, promote from within, or poach another club's Head Coach. The latter involves a Head Coach quitting their current post to take up their new job, and the recruiting club is likely to have to pay a release clause to begin talks. One would assume that better or over performing Head Coaches are the primary targets for recruiting clubs. However, the effect on the performance of the club losing their Head Coach is unclear since the clubs would not necessarily have planned for this event (unlike a dismissal) and had no intentions to let their current Coach leave. It is therefore unclear, a priori, what impact a Head Coach quit will have on team performance. 
In their review of the recent literature on Head Coaches and football team performance, Van Ours and Van Tuijl (2016) identify eleven studies published since 2000 analysing the period 1993-2010 spanning six countries. None of them identify a positive effect of an incoming Coach following a Coach dismissal. However, there are some important limitations to the studies reviewed. First, with the exception of Dobson and Goddard (2011), they rely on a small number of Coach dismissal observations, and typically in a single league. Second, they tend to report changes over relatively short periods of time (usually four games) which may be insufficient to pick up performance changes if Head Coaches take some time to "make their mark", which appears likely given the need to adjust to a new environment and alter the composition of the team through hires and fires. Third, the studies rely on difference-in-difference estimates that do not provide a convincing counterfactual to the dismissal spells.

Van Ours and Van Tuijl (2016) address some of these issues. In particular, they deploy a nearest neighbour matching strategy using the gap between team performance and expected performance (using betting odds) to match team spells with dismissals against team spells for the same football team that experienced similar patterns in performance and expected performance but did not switch Head Coach. This strategy offers a much more plausible counterfactual against which to judge the performance effects of an incoming Head Coach. They find performance improves after Coach dismissal, but the same improvement is observed in counterfactual cases, leading the authors to conclude that they are simply observing "a regression to the mean phenomenon" (p. 602). However, their study also suffers from small sample sizes, something that particularly affects their ability to estimate models for the subset of cases where Head Coaches quit. They also combine estimates for short and long follow-up spells without identifying the short and long-run effects of a Coach switch.

Madum (2016) also investigates team performance after Head Coach departures with a nearest neighbour matching estimator. The matching estimator includes recent performance of the team and its opponent, as well as their league ranking, but not expected performance derived from betting odds. Exploiting game-level data in the top division of Danish football over 19 seasons he finds teams improve their performance after firing a Coach, relative to counterfactual scenarios, but the performance only improves in home games. This finding is similar to Tena and Forrest (2007) for Spain 
although they did not use matching methods..$^{5}$ Madum also shows that the effect is apparent only for those teams that fired Coaches (the average treatment-on-the-treated effect) but that the effect would have been absent among the non-treated, a finding that suggests team owners behave optimally when deciding whether to dismiss poorly performing Coaches.

Since Head Coaches in professional football typically have the power to recruit football players to the squad and backroom support staff, pick the team for each game, and decide on match tactics, it would not be surprising to find that teams who fire poorly performing Coaches see performance improve with an in-coming Coach. Yet this is not what is found in Van Ours and Van Tuijl (2016) nor in most of the literature. Madum is one of the few exceptions. Furthermore, if owners are behaving optimally as principals in firing poorly performing agents we would not expect the same effects when estimating treatment-onthe-non-treated. This is precisely what Madum finds. However, both Van Ours and Van Tuijl (2016) and Madum (2016) are constrained in estimating effects of quits due to their small sample sizes. Quits are decisions taken by agents, rather than principals, so there might be less likelihood that they will be correlated with improvements in team performance, at least in the longer term.

Our estimates differ somewhat from those in the literature in three respects. First, our sample sizes are large enough to generate sufficient statistical power to be reasonably confident of identifying even quite small Head Coach effects on performance for both dismissals and quits. Second, we estimate performance outcomes over a longer period (20 games) to establish whether any effects of a Coach change differ in the short and longer term. Third, we use entropy balancing to construct counterfactual spells to those ending in quits or dismissals. This technique, described in detail in Section Three, has not been used previously in the literature.

We test the hypothesis that fires result in performance improvements, not withstanding the caveats outlined above, but quits are less likely to do so. Because we track Head Coaches over long periods of time, we are able to compare and contrast short-run and

\footnotetext{
${ }^{5}$ In contrast, Muehlheusser et al. (2016) find performance improvements among German teams are driven by away matches.
} 
medium-run performance effects, as well as effects across seasons. This distinction between shorter- and longer-run causal impacts is important in picking up quite separate effects of Head Coach changes on team performance. The short-run effect is the "bump" in performance that is attributable to simply making a change. There are two aspects to this. The first is the one football pundits often refer to, namely the potential motivational impact of a new Coach on current players who are seeking to impress the new Coach in order to cement their place in the team. The second element that might have an immediate impact on performance is simply the fact of having made a change. Levitt (2016) finds there are happiness benefits of making life-changing decisions when determined by the toss of a coin - that is, even when the decision is made based on a random event. Analogously, it seems reasonable to assume that a simple change in Coach - regardless of the in-coming Coach's quality or the circumstances surrounding his appointment - may result in improvements in team performance. Both these "bump" effects might apply to scenarios in which a Coach has quit as well as dismissals.

The longer-run causal impact of a change in Head Coach will arise where Coaches benefit from on-the-job learning including learning about the new football club, its players and the expectations and orientation of the owners. Coaches will also be able to sell unwanted players and recruit new ones via the transfer market. Recent studies emphasise the importance of on-the-job learning for individual worker productivity (e.g. Gaynor et al. (2005) in the health economics literature), especially among new hires (de Grip, 2015). ${ }^{6}$ We look directly at time-variance in any performance effects.

Our study is also distinctive because, to our knowledge, all other studies to date focus on single countries. Our data are from four countries (Germany, Italy, Spain and France). We know from other studies that the labour markets in these countries operate quite differently due to differences in employment protection, for example (European

\footnotetext{
${ }^{6}$ Perhaps the most successful football club manager of all time, Sir Alex Ferguson, described the time it took to "build a club" (https://hbr.org/2013/10/fergusons-formula). Yet he was not successful in his early years as he recalled in his autobiography: "After the farewell in May 2013, the pivotal moments filled my thoughts. Winning that FA Cup third-round tie against Nottingham Forest in January 1990, in which a Mark Robins goal sent us on our way to the final when my job was supposedly on the line. Without the FA Cup [final] victory over Crystal Palace nearly four years after my arrival, grave doubts would have been raised about my suitability for the job. We will never know how close I was to being sacked, because the decision was never forced on the United board. But without that triumph at Wembley, the crowds would have shrivelled. Disaffection might have swept the club" (Ferguson, 2013).
} 
Commission, 2013). In football, differences in Head Coach labour markets may emerge due to variations in governance structures across countries, the financing of clubs, media attention, and team ownership. Examination of these differences is beyond the scope of the present paper, however.

\section{Data and Empirical Approach}

Our data set consists of all games from the top two divisions of four major European football leagues (France, Germany, Italy and Spain) over the period 2001/02 to 2014/15 for which we can precisely ascertain the start and end dates of managerial spells. ${ }^{7}$ This period covers 273 teams, with 769 individual Coaches taking charge of games for those teams. Coaching tenures were hand-collected from Wikipedia, supported by online newspaper sources from each country. In line with literature such as van Ours and van Tuijl (2016), we exclude caretaker spells where an interim Coach took over management of a team prior to a permanent appointment. It could be that an interim candidate performs well enough to be given the job on a full-time basis; in this case we only consider the date from when they were permanently appointed. In aggregate, we have 1,327 fires and 533 quits, which on average lasted for 35 (std. dev. = 31) and 60 (std. dev. = 51) games respectively. Table 1 shows the number of dismissals and quits per season, aggregated over the leagues in our data. Dismissals exceed quits and there appears to be a rising trend in both dismissals and quits. The increased firing rate may be a consequence of growing revenue differences between league positions generally in European football. ${ }^{8}$ This increase in reward for success was proposed by d'Addona and Kind (2014) as an explanation for increased Head Coach turnover in English football in their study covering the post-war period up to 2008.

\footnotetext{
${ }^{7}$ We exclude the English leagues from our analysis since many teams in England operate with a Manager rather than a Head Coach. Typically, a Manager will be involved in the same roles as a Head Coach (coaching the team, picking the matchday squads, motivating players etc.) with the added responsibility of recruitment and overseeing the youth teams. In European football, teams now typically operate with a Head Coach and a Director of Football or General Manager taking on the other responsibilities with input from the Head Coach.

${ }^{8}$ Prominent amongst the sources of revenue differences between league positions is the growth of UEFA Champions' League revenues for the top three or four teams that qualify for this competition from our four sample Leagues. These revenues have grown substantially over time prompting increased investment in playing squads by aspiring teams (Green et al., 2015).
} 
Table 1: Frequency of Exits (by type) per season

\begin{tabular}{lrr}
\hline Season & Dismissals & \multicolumn{1}{c}{ Quits } \\
\hline $2000-01$ & 70 & 20 \\
$2001-02$ & 61 & 34 \\
$2002-03$ & 63 & 26 \\
$2003-04$ & 71 & 43 \\
$2004-05$ & 63 & 36 \\
$2005-06$ & 74 & 31 \\
$2006-07$ & 79 & 39 \\
$2007-08$ & 69 & 34 \\
$2008-09$ & 95 & 44 \\
$2009-10$ & 112 & 29 \\
$2010-11$ & 99 & 38 \\
$2011-12$ & 111 & 39 \\
$2012-13$ & 99 & 36 \\
$2013-14$ & 110 & 28 \\
$2014-15$ & 151 & 56 \\
\hline Total & 1327 & 533 \\
\hline
\end{tabular}

Figure 1 shows the timing of dismissals and quits respectively as the season progresses. Time lapsed is measured monthly (as opposed to say, number of games) since the different countries and different tiers within a country have different season lengths. ${ }^{9}$ There are large spikes in Coach departures at the end of the season (usually May, though a season occasionally extends into June). This makes sense on several counts. The off season is a period with no games other than pre-season friendlies and coincides with the summer transfer window. Together, these give a new appointment the best opportunity to work with their new squad and implement any changes they deem necessary. This could entail working with the current squad of players, honing their skills, developing a playing style and making use of the transfer market to recruit new players to the team. Moreover, the off-season is when many Head Coach contracts expire or are reviewed by the board of directors, so teams wishing to dismiss their Coach may find it best to wait until contract expiry, rather than sacking mid-season which may require a substantial severance payment to the Coach.

\footnotetext{
${ }^{9}$ The number of teams in our leagues per season varies between 18 and 24, and as such season length varies between 34 and 46 games. Due to restructuring of leagues, bankruptcy and or disqualification of clubs, season length may vary from year to year.
} 

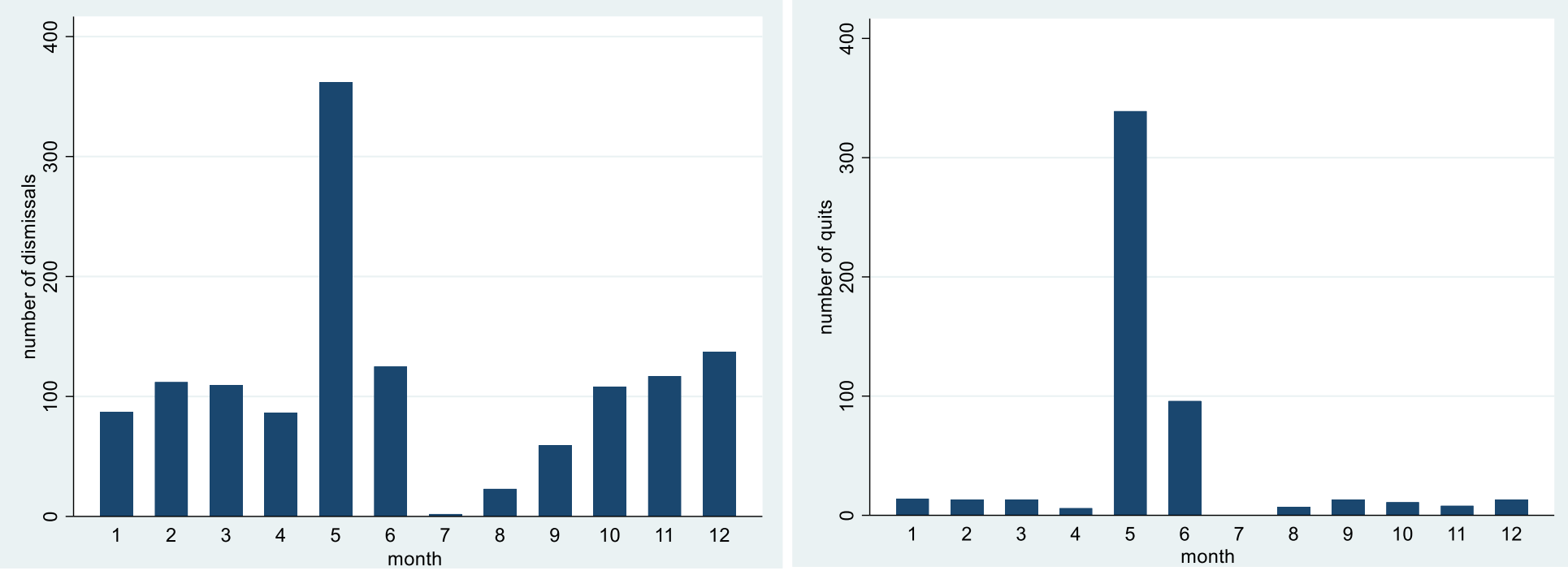

Figure 1: Frequency of Coach exits by month

During the season dismissals tend to peak in mid-season when some leagues have a winter break. Quits on the other hand show little pattern over time. It appears that many clubs reassess their prospects during the winter break and are more likely to fire their Head Coaches at this juncture than at other points in the season. Importantly for our analysis, the two histograms give a preliminary suggestion that the statistical processes driving Head Coach fires and quits could well be different.

Figure 2 shows average team performance before and after Coach changes, again with fires and quits considered separately. We assess team performance across the whole sample, up to 20 games before a Coach change and up to 20 games after the change, with team performance being measured as Mean Points Per Game. 20 games was chosen as this is approximately half a season, though for smaller leagues with shorter seasons this will be a little longer than half a season. The blue line refers to performance during a quit spell, and the red line refers to performance during a dismissal spell. 


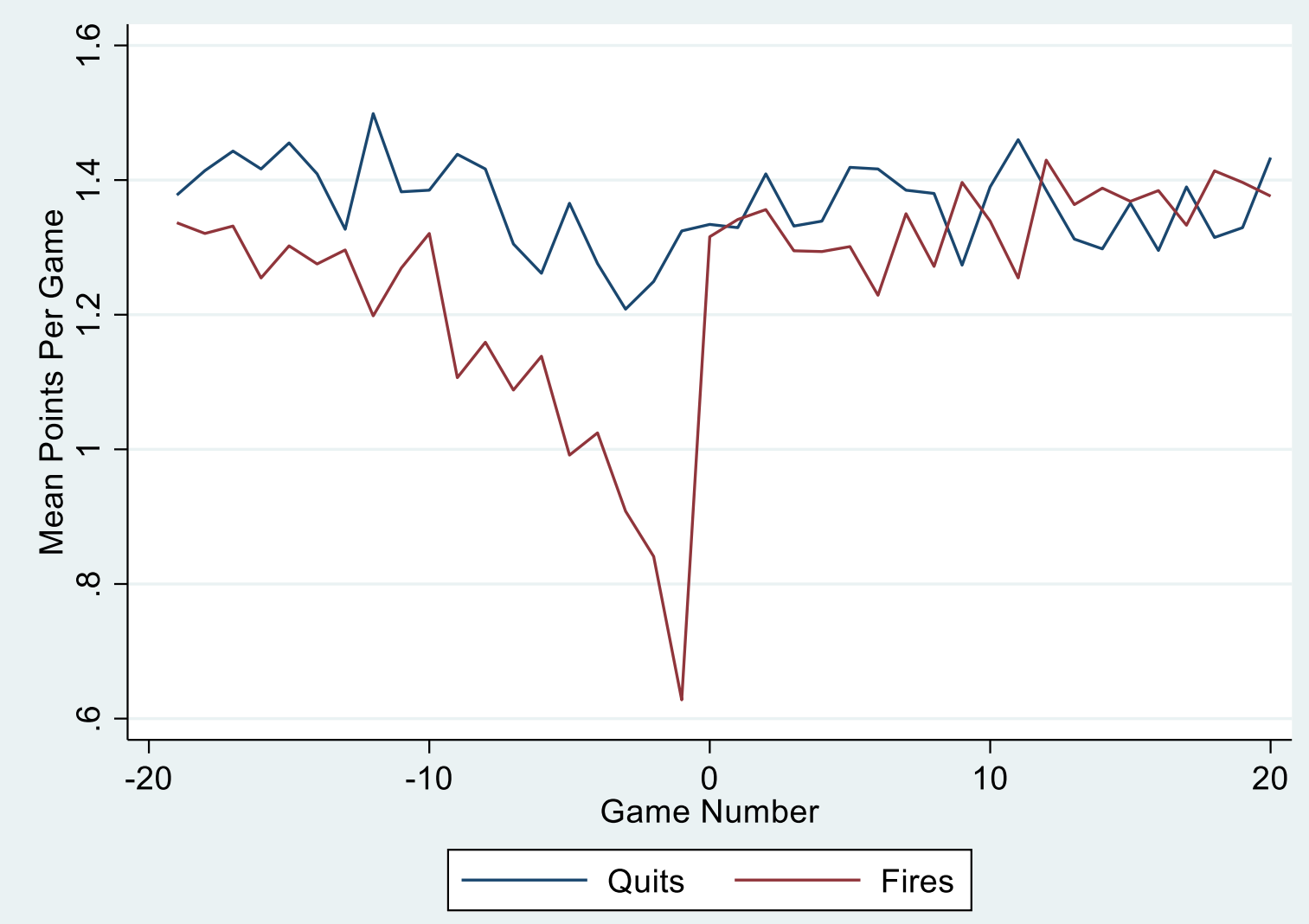

Figure 2: Points Per Game before and after a Coaching change

Prior to dismissals, team performance drops as indicated by the decline in the line representing fires as game number zero approaches. This is akin to the Ashenfelter Dip, something one needs to be mindful of when making over-time comparisons before-andafter Head Coach dismissals (Bruinshoofd and ter Weel, 2003). ${ }^{10}$ Post-dismissal team performance recovers and stabilises at a level close to that for the pre-period. In contrast, there is less evidence of a dip in performance prior to quits, nor much of a change in performance after a quit.

As de Paulo and Scoppa (2012) and van Ours and van Tuijl (2016) argue, the recovery in team performance following a Coach firing could simply be the result of regression to the mean. The key question that we address below in more formal regression analysis is whether we can discern any causal impact of Head Coach turnover on team performance

\footnotetext{
${ }^{10}$ The Ashenfelter Dip, first observed by Orley Ashenfelter (1978), describes the drop in the earnings of participants in job training programs in the year before entry. Thus, a simple before and after comparison of the effect of job training programs on earnings is likely to be overestimate the true effect.
} 
after accounting for the endogeneity of Head Coach change and other confounding factors.

Our empirical approach begins by specifying a naïve OLS regression as follows:

$$
Y_{i j k}=X_{i j k}^{\prime} \alpha+\beta d_{i j k}+\epsilon_{i j k}
$$

where the subscripts are denoted as $i$ for team, $j$ for game and $k$ for season. This is our outcome model, where the dependent variable, $Y_{i j k}$, is points per game: teams get three points for a win, one for a draw and none for a defeat. We run models for points obtained for spells of the next single game through to longer outcome spells of up to 20 games. Match results and betting odds (which we make use of later) were provided by www.football-data.co.uk. $d_{i j k}$ is our main variable of interest; a dummy variable to indicate whether there has been a coach change. Because we have two possible types of exit (quit or dismissal), we run the above specification twice to account for this, taking out coaching tenures that end in the other type of exit (i.e. we drop spells that end in a quit when analysing dismissals and vice versa). Naturally, our test that a coach change has a positive effect on performance is then a $t$-test of the null of $\beta=0$ in equation (1). $X_{i j k}$ is a vector of control variables which includes information on previous team performance, captured by points per game over the previous 10 fixtures, and performance relative to expected performance (called Surprise, described below). We also include opposition form, measured by the opponent's league positions, and home advantage, measured by the proportion of home games over the follow up period. To complete (1), $\varepsilon_{i j k}$ is a random error term. Throughout our estimations, standard errors are clustered at the team level.

Following van Ours and van Tuijl (2016) we incorporate a measure of Surprise which is the difference between actual and expected performance. Performance above or below or expectations in any given match, or indeed across multiple games are likely to affect future performance. ${ }^{11}$ Teams earn three points for a win, and one point for a draw, thus expected points in a given match is computed as:

\footnotetext{
${ }^{11}$ As well as predicting future outcomes, Surprise is a determinant of a team dismissing their Head Coach. This is a point we come to during our discussions on covariate balancing.
} 


$$
E(\text { Points })=(3 * \text { Prob.of Win })+\text { Prob. of Draw }
$$

where the probabilities are derived from bookmakers' betting odds. Surprise is then actual points minus expected points. Naturally, a Surprise value of 0 indicates that a team performed as expected, with this being reflected by the betting market. We include Surprise in the most recent game, cumulative (total) surprise over games lagged two to five and cumulative (total) surprise over games lagged six to ten to capture any longer runs of good or bad form.

The difficulty in relying on OLS estimation of Head Coach changes on team performance is that Head Coach changes are not random. Indeed, they are likely to be endogenous with respect to team performance. To put this another way, it is likely that only the poor or underperforming teams sack their coach, as is apparent in Figure 2. Consequently, we cannot infer what would have happened to a team's performance in the absence of a Head Coach change by comparing the performance of teams that did and did not make a change. De Paolo and Scoppa (2012), Van Ours and Van Tuijl (2016) and Besters et al. (2016) found positive and significant effects of Head Coach dismissals on team performance for Italian, Dutch and English football, respectively, from naïve OLS estimates only for these effects to become statistical insignificant when they compared performance with a matched comparator group.

We adopt a different approach to obtain the causal impact of Head Coach changes on team performance, namely Entropy Balancing (Hainmueller, 2012), implemented by the Stata command ebalance (Hainmueller and $\mathrm{Zu}, 2013$ ). This is a data pre-processing method that reweights observational data to achieve covariate balance in treatment and control groups. It does so by ensuring that the means, variances, skewness (and theoretically even higher moments) are equal for the covariates in the treatment and control groups. These weights are then simply used in a weighted version of the OLS regression described in (1). The weights ensure covariate balance across treated and control spells such that Head Coach departures are akin to a random process. Any selection into treatment is stripped out of the outcome equation (1). Estimates of our unweighted OLS regression can be found in the Appendix. 
More formally, following the notation in Hainmueller and $\mathrm{Zu}$ (2013), entropy balancing can be thought of as a generalised propensity score weighting approach to form a counterfactual mean as follows:

$$
\boldsymbol{E}(Y(0) \widehat{\mid D}=1)=\frac{\sum_{\{i \mid D=0\}} Y_{i} w_{i}}{\sum_{\{i \mid D=0} w_{i}}
$$

where $w_{i}$ is the entropy balancing weight for each observation in the control sample. The weights are chosen by the following scheme to minimise the entropy distance metric, defined by the loss function $h($.), which we can think of as being a measure of dissimilarity between two distributions.

$$
\min _{w_{i}} H(w)=\sum_{i \mid D=0} h\left(w_{i}\right)
$$

Subject to the following constraints

$$
\begin{aligned}
& \sum_{i \mid D=0} w_{i} c_{r i}\left(X_{i}\right)=m_{r} \quad r \in 1, \ldots, R \\
& \sum_{i \mid D=0} w_{i}=1 \\
& w_{i} \geq 0 \quad \text { for all } i \text { such that } D=0
\end{aligned}
$$

Where $c_{r i}\left(X_{i}\right)=m_{r}$ describes a set of $\mathrm{R}$ balance constraints imposed on the covariate moments in the reweighted control group. The second constraint is arbitrary, and the weights can sum to any constant. In the Stata procedure, $\mathrm{R}$ is set to 3 meaning we balance covariates on the mean, variance and skewness. Tables A4 and A5 in the appendix show these moments of our treatment and control groups before and after applying our entropy balancing weights.

Entropy Balancing has several advantages, both in a practical and an econometric sense, over more conventional weighting methods (such as Inverse Probability Weighting Regression Adjustment). From the researcher's point of view, the scheme removes the need for the continual iterative process of running a propensity score model and checking for covariate balance, not to mention the concern of mis-specifying the treatment model. Moreover, all observations receive a weight, meaning the whole sample is available for 
our estimations. ${ }^{12}$ Zhao and Percival (2017) also show that entropy balancing possesses the attractive property of being doubly robust, even though no treatment model is actually estimated, while also producing treatment effects that are within the range of observed outcomes.

The covariates we balance on are all variables that, at least in theory, should predict Head Coach departures. We follow Bryson et al. (2020) in our selection of covariates that affect departures, since they are also liable to influence performance outcomes. These capture a combination of team form, coaching characteristics and season progress. For an analysis of variables that are associated with both types of exit, see Table A3 in the Appendix, which displays the results of a multinomial logit regression. Team form variables include mean points per game over the last 10 games, league position (where position is captured as rank across both tiers per country) and the final league position of the team in the previous season. Since owners' (and stakeholders) expectations about performance (as well as actual performance) are likely to play a role in coaching departures, we also include the lagged cumulative Surprise variables as discussed earlier. Should performance slip below some acceptable level in the eyes of the principal, which will include knowledge about opponent quality, then the team may look to replace the Head Coach (van Ours and van Tuijl, 2016). A negative Surprise value is a likely signal of a poorly performing Head Coach.

Our measures of Head Coach characteristics include tenure at the current team (measured in number of games), experience (years since first coaching job), age and its square, the number of previous Head Coach spells, dummy variables capturing previous successes and failures as a coach (previous promotions, previous cup winners, and a previous relegation), and dummy variables capturing some kind of connection with the club, namely whether the coach was hired from within and whether the coach is an ex-player at the club. The latter two variables, along with tenure, can be thought of as club specific measures of human capital, while the other measures capture more general human capital i.e. skills and or experiences that are not specific to any one club. Finally, our measures of season progress (in line with Figure 1) include the proportion of games remaining (to

\footnotetext{
12 This means no observations are lost through the enforcement of common support, as is often the case in propensity score matching.
} 
account for differences in season length) and whether the departure occurred after the last game of the season. Descriptive statistics of our covariates and selected outcomes are shown in Table 2.

Table 2: Descriptive Statistics

\begin{tabular}{lrrrrr}
\hline Variable & Obs & Mean & Std. Dev. & Min & Max \\
\hline Outcomes & & & & & \\
Mean Points per game Next 1 Game & 65,998 & 1.391 & 1.293 & 0 & 3 \\
Mean Points per game Next 5 Games & 65,339 & 1.390 & 0.620 & 0 & 3 \\
Mean Points per game Next 10 Games & 64,494 & 1.391 & 0.481 & 0 & 3 \\
Mean Points per game Next 15 Games & 63,626 & 1.391 & 0.423 & 0.133 & 3 \\
Mean Points per game Next 20 Games & 62,751 & 1.391 & 0.390 & 0.150 & 2.900 \\
Team Performance & & & & & \\
Surprise t-1 & 66,157 & 0.014 & 1.198 & -2.707 & 2.797 \\
Surprise t-2 to t-5 & 66,157 & 0.061 & 2.371 & -8.269 & 8.277 \\
Surprise t-6 to t-10 & 66,157 & 0.080 & 2.649 & -9.681 & 9.760 \\
Mean Points per game Prev 10 Games & 66,157 & 1.395 & 0.479 & 0 & 3 \\
Position & 66,157 & 19.927 & 12.524 & 1 & 48 \\
Last Season Position & 66,157 & 28.377 & 21.872 & 1 & 66 \\
Coach Characteristics & & & & & \\
Tenure (n games) & 66,157 & 44.653 & 47.062 & 1 & 441 \\
Experience (years) & 66,157 & 11.475 & 7.707 & 0 & 44 \\
Age & 66,157 & 48.439 & 6.582 & 30.212 & 73.739 \\
N Prev HC Jobs & 66,157 & 4.395 & 3.888 & 0 & 23 \\
Previous Promotion & 66,157 & 0.525 & 0.499 & 0 & 1 \\
Previous Cup & 66,157 & 0.195 & 0.397 & 0 & 1 \\
Previous Relegation & 66,157 & 0.268 & 0.443 & 0 & 1 \\
Internal & 66,157 & 0.138 & 0.345 & 0 & 1 \\
Ex Player & 66,157 & 0.160 & 0.366 & 0 & 1 \\
Season Progress & & & & & \\
Proportion of Games Remaining & 66,157 & 0.484 & 0.285 & 0 & 0.978 \\
Last Game of Season & 66,157 & 0.025 & 0.155 & 0 & 1 \\
\hline & & & & & \\
& & & & & \\
& & & & & \\
\end{tabular}

Our preferred variants of the entropy balanced models include team fixed effects, thus focusing on comparisons of team performance within team over time. In doing so we avoid biases in estimates of Head Coach departures arising from fixed unobservable differences across teams. We can also include season fixed effects in our estimations. Our baseline models compare spells ending in either a Head Coach quit or dismissal (at time $\mathrm{t}=0$ ), relative to counterfactual spells which did not end in a Head Coach departure, where we follow performance for a further 20 games $(t=1$ to $t=20)$, regardless of whether there are subsequent Head Coach changes in the period after $\mathrm{t}=0$. It is arguable that football 
results should count when estimating the impact of a Coach dismissal or quit, even if there is subsequent Coach turnover in the outcome spell. In a later analysis, we restrict our analyses to 'clean' spells of games where no subsequent Head Coach change occurs. This facilitates an assessment of the long-term performance of the initial Head Coach change, where that performance is permitted to develop. However, it is also arguable that in dropping spells with a subsequent Head Coach change, we are truncating the sample based on a potentially endogenous variable i.e. whether team owners choose to retain the Coach for another 20 games, since this will partly reflect how well the new Head coach is performing during that period. Indeed, a simple probit regression reveals that good performance (both absolute and relative to expectations), whether the team is promoted or relegated and the proportion of games remaining are all strong predictors of clean spells.

Unlike most other studies which confine analysis to within-season changes in Head Coach, we allow team performance history to straddle seasons and we also include between-season Coach changes in our analysis. We test the sensitivity of this by running analyses with and without closed season Coach changes, as it is possible that those changes that occur in the closed season are qualitatively different to those that occur within season. For example, they may include a larger number of contract non-renewals. There are not enough within season quits to extract any meaningful results, hence our soul focus here will be on dismissals. Of the 1,327 total dismissals, 883 occurred within season, and the remaining 444 occurred during the offseason. Our spells of games may also include instances of teams being promoted and relegated. Of course, a win is worth three points and a draw one point in both the first and second tier, but due to the quality of opponents in the top tier, a win is likely harder to come by for promoted teams. Equally, a relegated team should find it easier to pick up points in the lower tier. This could play on owner's expectations, and so we check the robustness of our results by taking out teams who are playing in their first season after a promotion or relegation. 


\section{Results}

\subsection{Baseline Entropy Balance Models}

We start by presenting our baseline models, using the entropy balanced weights as specified by the Stata routine in a weighted version of equation (1), including team and season fixed effects in various specifications. Table 3 displays the results for dismissals, while Table 4 displays the results for quits. Both sets of results suggest that team performance does not significantly improve for any sustained run of games following either a dismissal or a quit. The effect of including of team fixed effects is to reduce the point estimates. Including team fixed effects means we are relying on spells of games within team to obtain our counterfactual spells. If these omitted differences are correlated with the tendency to change Coaches, then the estimates without team fixed effects will be biased, with the team fixed effects soaking up a great deal of the across team differences. In practical terms, any positive effects of a coaching change may be limited to a select number of teams.

Of course, these are all average effects, but within that average will lie a range of outcomes, with some teams benefitting from changing Coach, while other will likely suffer. Even if teams know the average effect is negligible, they may be attracted by the small probability of a successful Coach change. On the other hand, this zero average effect could be consistent with the scapegoat hypothesis of fan disgruntlement and pressure (e.g. Tena and Forrest, 2007), in that a change is made simply to appease disgruntled fans, even though performance is unlikely to improve. Nevertheless, we feel that jumping to the conclusion of 'Head Coaches make no difference' on the basis of these results is possibly a little short sighted given our theoretical discussion outlined in Section 2. Hence, we offer alternative specifications to look at this in more depth. 
Table 3: Entropy Balanced OLS (Dismissals)

\begin{tabular}{ccccccccccc} 
& \multicolumn{2}{c}{ no FE } & \multicolumn{2}{c}{ team FE } & season FE & N & \multicolumn{2}{c}{ Adj. R2 } & Team & Season \\
Mean Points Next ... Games & Coeff & s.e. & Coeff & s.e. & Coeff & s.e. & & No FE & FE & FE \\
\hline 1 & -0.008 & $(0.043)$ & 0.011 & $(0.045)$ & -0.016 & $(0.042)$ & 65,603 & 0.084 & 0.144 & 0.089 \\
2 & 0.032 & $(0.033)$ & 0.028 & $(0.035)$ & 0.030 & $(0.033)$ & 65,440 & 0.056 & 0.112 & 0.061 \\
3 & $0.048^{*}$ & $(0.028)$ & 0.039 & $(0.030)$ & $0.047 *$ & $(0.028)$ & 65,275 & 0.074 & 0.137 & 0.079 \\
4 & 0.038 & $(0.025)$ & 0.028 & $(0.026)$ & 0.037 & $(0.025)$ & 65,110 & 0.073 & 0.143 & 0.078 \\
5 & 0.015 & $(0.022)$ & 0.005 & $(0.023)$ & 0.014 & $(0.022)$ & 64,944 & 0.086 & 0.160 & 0.090 \\
6 & 0.004 & $(0.021)$ & -0.007 & $(0.021)$ & 0.003 & $(0.020)$ & 64,778 & 0.092 & 0.181 & 0.096 \\
7 & -0.007 & $(0.019)$ & -0.021 & $(0.019)$ & -0.008 & $(0.019)$ & 64,612 & 0.100 & 0.198 & 0.106 \\
8 & -0.006 & $(0.019)$ & -0.019 & $(0.018)$ & -0.006 & $(0.018)$ & 64,443 & 0.103 & 0.210 & 0.107 \\
9 & -0.015 & $(0.018)$ & $-0.031 *$ & $(0.018)$ & -0.014 & $(0.018)$ & 64,273 & 0.109 & 0.227 & 0.114 \\
10 & -0.002 & $(0.017)$ & -0.019 & $(0.016)$ & -0.001 & $(0.017)$ & 64,101 & 0.124 & 0.242 & 0.129 \\
11 & -0.002 & $(0.016)$ & -0.016 & $(0.015)$ & -0.001 & $(0.016)$ & 63,929 & 0.127 & 0.256 & 0.132 \\
12 & -0.006 & $(0.016)$ & -0.021 & $(0.014)$ & -0.006 & $(0.016)$ & 63,755 & 0.134 & 0.269 & 0.139 \\
13 & 0.001 & $(0.015)$ & -0.013 & $(0.013)$ & 0.001 & $(0.015)$ & 63,582 & 0.134 & 0.283 & 0.140 \\
14 & 0.005 & $(0.015)$ & -0.009 & $(0.013)$ & 0.005 & $(0.015)$ & 63,409 & 0.145 & 0.298 & 0.152 \\
15 & 0.005 & $(0.015)$ & -0.009 & $(0.013)$ & 0.005 & $(0.015)$ & 63,235 & 0.147 & 0.312 & 0.154 \\
16 & 0.006 & $(0.015)$ & -0.009 & $(0.013)$ & 0.006 & $(0.015)$ & 63,059 & 0.147 & 0.320 & 0.155 \\
17 & 0.011 & $(0.015)$ & -0.004 & $(0.012)$ & 0.011 & $(0.014)$ & 62,885 & 0.153 & 0.327 & 0.160 \\
18 & 0.011 & $(0.014)$ & -0.006 & $(0.012)$ & 0.011 & $(0.014)$ & 62,711 & 0.154 & 0.333 & 0.162 \\
19 & 0.017 & $(0.014)$ & 0.000 & $(0.011)$ & 0.017 & $(0.014)$ & 62,535 & 0.155 & 0.342 & 0.163 \\
20 & 0.016 & $(0.014)$ & -0.002 & $(0.011)$ & 0.017 & $(0.014)$ & 62,360 & 0.154 & 0.352 & 0.162 \\
\hline
\end{tabular}

Cluster Robust Standard Errors in Parentheses (clustered at the Team level) *p<0.1, **p<0.05, ***p<0.01 
Table 4: Entropy Balanced OLS (Quits)

$\begin{array}{lllll}\text { no FE team FE } & \text { season FE } & \mathrm{N} & \text { Adj. R2 }\end{array}$

\begin{tabular}{ccccccccccc} 
Mean Points Next ... Games & Coeff & s.e. & Coeff & s.e. & Coeff & s.e. & & No FE & FE & \multicolumn{2}{c}{ Season } \\
\hline 1 & 0.020 & $(0.066)$ & -0.031 & $(0.073)$ & 0.022 & $(0.067)$ & 65,048 & 0.152 & 0.281 & 0.157 \\
2 & -0.002 & $(0.050)$ & -0.008 & $(0.054)$ & -0.007 & $(0.050)$ & 64,888 & 0.092 & 0.232 & 0.100 \\
3 & 0.023 & $(0.048)$ & 0.011 & $(0.051)$ & 0.019 & $(0.048)$ & 64,725 & 0.100 & 0.253 & 0.103 \\
4 & 0.004 & $(0.042)$ & 0.000 & $(0.043)$ & 0.004 & $(0.042)$ & 64,561 & 0.105 & 0.269 & 0.110 \\
5 & 0.003 & $(0.038)$ & -0.010 & $(0.039)$ & 0.005 & $(0.039)$ & 64,396 & 0.113 & 0.279 & 0.117 \\
6 & 0.016 & $(0.035)$ & 0.005 & $(0.036)$ & 0.016 & $(0.036)$ & 64,232 & 0.116 & 0.301 & 0.119 \\
7 & 0.017 & $(0.033)$ & 0.003 & $(0.033)$ & 0.017 & $(0.033)$ & 64,069 & 0.126 & 0.326 & 0.130 \\
8 & 0.012 & $(0.031)$ & -0.002 & $(0.031)$ & 0.011 & $(0.032)$ & 63,902 & 0.138 & 0.361 & 0.141 \\
9 & 0.006 & $(0.030)$ & -0.013 & $(0.030)$ & 0.006 & $(0.030)$ & 63,736 & 0.141 & 0.367 & 0.145 \\
10 & 0.000 & $(0.029)$ & -0.020 & $(0.029)$ & 0.000 & $(0.029)$ & 63,569 & 0.161 & 0.398 & 0.165 \\
11 & -0.009 & $(0.028)$ & -0.032 & $(0.027)$ & -0.008 & $(0.028)$ & 63,398 & 0.166 & 0.408 & 0.171 \\
12 & -0.003 & $(0.026)$ & -0.024 & $(0.025)$ & -0.001 & $(0.026)$ & 63,228 & 0.178 & 0.423 & 0.183 \\
13 & 0.004 & $(0.026)$ & -0.019 & $(0.025)$ & 0.006 & $(0.026)$ & 63,058 & 0.183 & 0.435 & 0.189 \\
14 & 0.005 & $(0.025)$ & -0.018 & $(0.024)$ & 0.006 & $(0.025)$ & 62,888 & 0.197 & 0.452 & 0.203 \\
15 & -0.003 & $(0.024)$ & -0.022 & $(0.023)$ & -0.002 & $(0.024)$ & 62,714 & 0.198 & 0.452 & 0.202 \\
16 & -0.003 & $(0.023)$ & -0.022 & $(0.023)$ & -0.002 & $(0.023)$ & 62,542 & 0.205 & 0.460 & 0.209 \\
17 & -0.008 & $(0.023)$ & -0.025 & $(0.022)$ & -0.008 & $(0.023)$ & 62,371 & 0.210 & 0.470 & 0.214 \\
18 & -0.006 & $(0.022)$ & -0.018 & $(0.021)$ & -0.005 & $(0.022)$ & 62,200 & 0.224 & 0.481 & 0.228 \\
19 & -0.010 & $(0.022)$ & -0.022 & $(0.021)$ & -0.008 & $(0.022)$ & 62,030 & 0.228 & 0.489 & 0.232 \\
20 & -0.008 & $(0.021)$ & -0.022 & $(0.020)$ & -0.006 & $(0.021)$ & 61,856 & 0.228 & 0.498 & 0.233 \\
\hline
\end{tabular}

Cluster Robust Standard Errors in Parentheses (clustered at the Team level) $* \mathrm{p}<0.1, * * \mathrm{p}<0.05, * * * \mathrm{p}<0.01$ 


\subsection{Alternative Specifications}

\subsubsection{Clean Follow Up Spell}

We define a 'clean' follow up spell as one where no subsequent Coaching change occurs after the initial change at $\mathrm{t}=0$. In other words, we are considering teams who stick with their new Coach. Under this definition, both quits and dismissals now show evidence of positive returns after changing a Head Coach (Tables 5 and 6), a result which also holds with the inclusion of team fixed effects. ${ }^{13}$ Despite the limitations discussed in Section 3 of this approach, there is still great value in these estimations, as we are likely capturing an upper bound of the effects of a Head Coach change. Given that these teams are likely happy with their new appointment, compared to teams who are unhappy and change Coaches again, this selection of 'clean' spells drops cases where the new appointment has been less successful.

While the results of positive effects of a Head Coach change are particularly evident for dismissals, we also observe some positive effects following a quit, though the effects occur much later in the follow up period. It could be that a new appointment following a quit takes longer to adjust to the new club, if for example they are still appointing their backroom staff or figuring out their best team having not had time to plan unlike the situation following a dismissal. With that being said, given that in these 'clean' follow up spells teams are likely happy with their new appointment, regardless of the manner of exit of the previous coach, then perhaps we should not be surprised to see longer term improvements to performance due to the learning process and adjustment period following a new appointment. This could have implications for team hiring policies and the process they go through to select a Head Coach. There is no official interview process that teams must go through, and teams often have a new appointment lined up even before they have dismissed the incumbent coach. Without taking the time to interview and carefully select candidates, it is possible the wrong hire is made with a low job match surplus.

\footnotetext{
${ }^{13}$ Spells that last 20 games or fewer represents a fairly sizeable portion of our data. $34 \%$ percent of Head Coach spells are over by or on the $20^{\text {th }}$ game. Over $13 \%$ of coaches don't even last until the $10^{\text {th }}$ game. These short spells are predominantly occurring in Italy and Spain.
} 
Table 5: Entropy Balanced OLS (Dismissals) with a clean follow up spell

\begin{tabular}{|c|c|c|c|c|c|c|c|c|c|c|}
\hline \multirow[b]{2}{*}{ Mean Points Next ... Games } & \multicolumn{2}{|c|}{ no FE } & \multicolumn{2}{|c|}{ team FE } & \multicolumn{2}{|c|}{ season FE } & \multirow[t]{2}{*}{$\mathbf{N}$} & \multicolumn{2}{|c|}{ Adj. R2 } & \multirow[b]{2}{*}{$\begin{array}{l}\text { Season } \\
\text { FE }\end{array}$} \\
\hline & Coeff & s.e. & Coeff & s.e. & Coeff & s.e. & & No FE & $\mathrm{FE}$ & \\
\hline 1 & 0.013 & $(0.044)$ & 0.051 & $(0.045)$ & 0.003 & $(0.043)$ & 65,461 & 0.085 & 0.139 & 0.090 \\
\hline 2 & 0.054 & $(0.034)$ & 0.058 & $(0.035)$ & 0.051 & $(0.034)$ & 65,297 & 0.052 & 0.107 & 0.055 \\
\hline 3 & $0.064 * *$ & $(0.028)$ & $0.056^{*}$ & $(0.030)$ & $0.062 * *$ & $(0.029)$ & 65,131 & 0.071 & 0.133 & 0.073 \\
\hline 4 & $0.071 * * *$ & $(0.025)$ & $0.057 * *$ & $(0.027)$ & $0.070 * * *$ & $(0.025)$ & 64,956 & 0.069 & 0.138 & 0.074 \\
\hline 5 & $0.056 * *$ & $(0.022)$ & 0.036 & $(0.023)$ & $0.055 * *$ & $(0.022)$ & 64,783 & 0.084 & 0.158 & 0.088 \\
\hline 6 & $0.046^{* *}$ & $(0.021)$ & 0.024 & $(0.022)$ & $0.045^{* *}$ & $(0.021)$ & 64,609 & 0.088 & 0.179 & 0.091 \\
\hline 7 & $0.042 * *$ & $(0.020)$ & 0.019 & $(0.020)$ & $0.042 * *$ & $(0.020)$ & 64,428 & 0.096 & 0.196 & 0.100 \\
\hline 8 & $0.041^{* *}$ & $(0.020)$ & 0.016 & $(0.019)$ & $0.041 * *$ & $(0.020)$ & 64,253 & 0.101 & 0.208 & 0.104 \\
\hline 9 & $0.039 * *$ & (0.019) & 0.009 & $(0.019)$ & $0.039 * *$ & $(0.019)$ & 64,069 & 0.108 & 0.229 & 0.112 \\
\hline 10 & $0.056 * * *$ & $(0.018)$ & $0.030 *$ & $(0.017)$ & $0.056^{* * * *}$ & $(0.018)$ & 63,880 & 0.127 & 0.255 & 0.132 \\
\hline 11 & $0.061 * * *$ & (0.018) & $0.036 * *$ & $(0.016)$ & $0.062 * * *$ & $(0.018)$ & 63,684 & 0.132 & 0.270 & 0.137 \\
\hline 12 & $0.059 * * *$ & $(0.018)$ & $0.031 *$ & $(0.016)$ & $0.059 * * *$ & $(0.018)$ & 63,494 & 0.142 & 0.285 & 0.147 \\
\hline 13 & $0.066 * * *$ & (0.017) & $0.039 * * *$ & $(0.015)$ & $0.066 * * *$ & $(0.017)$ & 63,312 & 0.147 & 0.302 & 0.152 \\
\hline 14 & $0.072 * * *$ & $(0.017)$ & $0.045^{* * *}$ & $(0.014)$ & $0.071 * * *$ & $(0.017)$ & 63,128 & 0.157 & 0.315 & 0.162 \\
\hline 15 & $0.081 * * *$ & $(0.017)$ & $0.051 * * *$ & $(0.015)$ & $0.080 * * *$ & $(0.017)$ & 62,933 & 0.165 & 0.332 & 0.170 \\
\hline 16 & $0.080 * * *$ & $(0.017)$ & $0.050 * * *$ & $(0.014)$ & $0.080 * * *$ & $(0.017)$ & 62,743 & 0.165 & 0.339 & 0.172 \\
\hline 17 & $0.091 * * *$ & $(0.017)$ & $0.060 * * *$ & $(0.014)$ & $0.090 * * *$ & $(0.017)$ & 62,551 & 0.172 & 0.349 & 0.178 \\
\hline 18 & $0.097 * * *$ & (0.016) & $0.063 * * *$ & $(0.013)$ & $0.096 * * *$ & $(0.016)$ & 62,364 & 0.180 & 0.360 & 0.187 \\
\hline 19 & $0.110 * * *$ & $(0.016)$ & $0.073 * * *$ & $(0.013)$ & $0.109 * * *$ & $(0.016)$ & 62,172 & 0.186 & 0.372 & 0.193 \\
\hline 20 & $0.112 * * *$ & $(0.015)$ & $0.075 * * *$ & $(0.012)$ & $0.112 * * *$ & $(0.015)$ & 61,980 & 0.189 & 0.383 & 0.195 \\
\hline
\end{tabular}

Cluster Robust Standard Errors in Parentheses (clustered at the Team level) $* \mathrm{p}<0.1, * * \mathrm{p}<0.05, * * * \mathrm{p}<0.01$ 
Table 6: Entropy Balanced OLS (Quits) with a clean follow up spell

\begin{tabular}{|c|c|c|c|c|c|c|c|c|c|c|}
\hline \multirow[b]{2}{*}{ Mean Points Next ... Games } & \multicolumn{2}{|c|}{ no FE } & \multicolumn{2}{|c|}{ team $\mathrm{FE}$} & \multicolumn{2}{|c|}{ season FE } & \multirow[t]{2}{*}{$\mathbf{N}$} & \multicolumn{3}{|c|}{ Adj. R2 } \\
\hline & Coeff & s.e. & Coeff & s.e. & Coeff & s.e. & & No FE & $\begin{array}{l}\text { Team } \\
\text { FE }\end{array}$ & $\begin{array}{l}\text { Season } \\
\text { FE }\end{array}$ \\
\hline 1 & 0.043 & $(0.070)$ & -0.005 & $(0.077)$ & 0.048 & $(0.071)$ & 65,003 & 0.147 & 0.274 & 0.154 \\
\hline 3 & 0.057 & (0.049) & 0.050 & $(0.053)$ & 0.056 & $(0.049)$ & 64,679 & 0.095 & 0.251 & 0.099 \\
\hline 4 & 0.029 & $(0.043)$ & 0.026 & $(0.044)$ & 0.031 & $(0.043)$ & 64,512 & 0.094 & 0.265 & 0.099 \\
\hline 5 & 0.038 & $(0.040)$ & 0.029 & $(0.041)$ & 0.042 & $(0.040)$ & 64,343 & 0.107 & 0.287 & 0.112 \\
\hline 8 & 0.036 & $(0.033)$ & 0.024 & $(0.033)$ & 0.038 & $(0.034)$ & 63,841 & 0.133 & 0.360 & 0.137 \\
\hline 9 & 0.037 & $(0.032)$ & 0.018 & $(0.032)$ & 0.040 & $(0.032)$ & 63,671 & 0.134 & 0.375 & 0.140 \\
\hline 10 & 0.024 & $(0.031)$ & 0.003 & $(0.030)$ & 0.026 & $(0.031)$ & 63,503 & 0.152 & 0.399 & 0.157 \\
\hline 11 & 0.030 & $(0.029)$ & 0.003 & $(0.029)$ & 0.031 & $(0.029)$ & 63,326 & 0.166 & 0.409 & 0.172 \\
\hline 12 & 0.037 & $(0.027)$ & 0.008 & $(0.026)$ & 0.038 & $(0.027)$ & 63,151 & 0.176 & 0.419 & 0.181 \\
\hline 13 & $0.053 *$ & $(0.027)$ & 0.020 & $(0.026)$ & $0.055^{* *}$ & $(0.028)$ & 62,974 & 0.183 & 0.428 & 0.188 \\
\hline 18 & $0.080 * * *$ & $(0.024)$ & $0.050 * *$ & $(0.023)$ & $0.080 * * *$ & $(0.025)$ & 62,080 & 0.232 & 0.476 & 0.234 \\
\hline 19 & $0.085 * * *$ & $(0.025)$ & $0.055 * *$ & $(0.023)$ & $0.085 * * *$ & $(0.025)$ & 61,902 & 0.238 & 0.493 & 0.240 \\
\hline 20 & $0.091 * * *$ & $(0.024)$ & $0.061 * * *$ & $(0.022)$ & $0.091 * * *$ & $(0.024)$ & 61,722 & 0.238 & 0.501 & 0.240 \\
\hline
\end{tabular}

Cluster Robust Standard Errors in Parentheses (clustered at the Team level) *p<0.1, **p<0.05, ***p $<0.01$ 
Table 7: Within and Between Season Dismissals

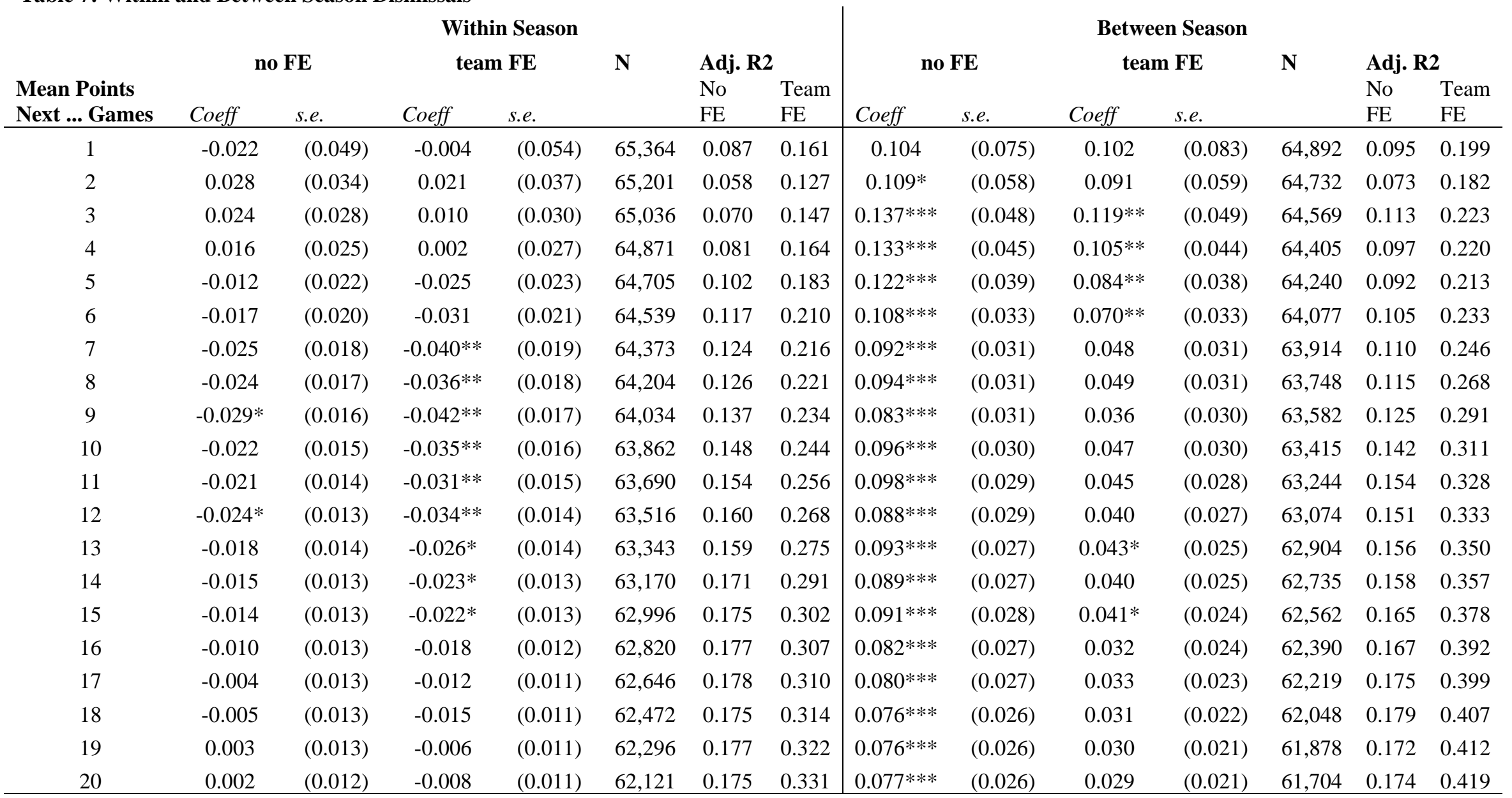

Cluster Robust Standard Errors in Parentheses (clustered at the Team level) *p<0.1, ${ }^{*} \mathrm{p}<0.05,{ }^{* * *} \mathrm{p}<0.01$ 


\subsubsection{Within and Between Season changes}

In Table 7, we distinguish between dismissals that took place during the season (left hand side of Table 7), and those that took place between seasons (right hand side). To obtain these results, we remove the Last Game of Season variable from the balancing scheme for within season dismissals, and Last Game of Season and Season Progress are removed from the balancing scheme for the offseason dismissal results. Focusing on mid-season dismissals, changing Head Coach appears to make little difference to team performance, while the fixed effects model suggests that team performance declines somewhat over games 7-15. If we instead focus only on coaching changes during the offseason (following a dismissal), team performance improves across the whole follow up period (apart from the first game of the season). The fixed effects variant also maintains some significance in the early part of the season. This distinction can be explained by Head Coaches being given the time to implement their new ideas and methods during pre-season training, as well as having access to the summer transfer window, where they can sell unwanted players, and bring in new players to improve their squad. Coaches who are hired mid-season are not afforded the opportunity to work with their squad without the burden of matches.

\subsubsection{Promotions and Relegations}

As a final check, we consider the role of promotions and relegations in our estimations. Results tables can be found in the appendix, tables A6 and A7. Results are largely unchanged from our baseline specification, though the team fixed effects variant of our dismissals model when taking out promoted teams shows some evidence of a bump to performance early in the new coach's tenure. By excluding newly promoted teams, who are likely to be lower in the table and perhaps struggling to adapt to the higher division, and thus a new coach will find it harder to have any impact. This is short lived however, and so the main interpretation of results remains unchanged. 


\section{Conclusions}

Using a large linked employer-employee data set for professional football in four countries we tackle the endogeneity of leadership change so as to evaluate the effects of changing a Head Coach on team performance. The professional football setting is useful in trying to isolate the causal impact of leadership on organisational performance, partly because the industry does not usually suffer from the exogenous shocks that afflict many other industries which make it harder to attribute performance change to management. The setting also means

principals who hire and fire their managers - Head Coaches in this setting - benefit from quick and frequent updating of firm performance because football teams tend to play one or two games per week during the football season.

Even though there is a strong theoretical argument to suggest that leadership changes in football could, and should make a difference, our estimates using entropy balancing fail to show any consistent gains to performance when compared to unconstrained counterfactual scenarios in which teams suffer similar runs of form but do not immediately dismiss their Head Coach. The finding is largely in keeping with other studies which suggest regression to the mean can explain the lack of sustained positive effects of Head Coach changes on football team performance.

However, we find a strong exception to this conventional result. We estimate what is likely to be an upper bound of the effect of managerial change by examining the effects of a Coach change among teams who make no subsequent coaching change in the 20 games after making a change. Using these constrained spells, we find teams can experience positive returns after a dismissal of between 0.04-0.1 points per game. Even though the magnitude is rather small in a sporting sense, this could well prove the difference between relegation and staying up or qualifying for a European competition or not which are undoubted signs of success. We believe this finding highlights the importance of a good job match, rather than continually changing coaches. 
In contrast, we find little evidence of performance effects following a Head Coach voluntarily quitting, though some longer-term effects are present in our 'clean' follow up spells. These findings are consistent with economic theory as laid out by Farber (1999). Dismissals are triggered by principals (team owners) rather than agents (employed coaches). The dismissal is itself triggered by poor team performance which is a signal of a bad job match. The owner uses his acquired information on the Head Coach's ability and productivity to terminate the relationship and aims to secure a better job match with a new hire. Quits are triggered by the agent rather than the principal with the departing Coach seeking better opportunities elsewhere (which include switching to a different job as well as different employer). Given that the job match was satisfactory to the employer (team owner) without consideration of the Coach's outside options then the best the employer can do is to replace the Coach with a job match that is just as good as the previous one. Our results show that team performance is neither improved nor impaired by Head Coach succession following a quit, suggesting that job matches between teams and voluntarily departing coaches were, on average, efficient. Nevertheless, longer term performance improvements are still possible because of a learning process.

As to why we see some differing effects in the short run and in the longer run, depending on specification, we conjecture that two effects could explain this. In the short run, there is a motivational effect of a new Head Coach where players are keen to impress the new leader. Recall that most teams that fire a Head Coach do so after experiencing a decline in performance. Given that it takes time to reequip a playing squad, the existing players have a time window in which to impress the incoming Head Coach to avoid being dropped or transferred. This would explain any upturns in form we observe during some specifications. In the medium to longer term, new coaches have to learn about their new team and its infrastructure very quickly given pressures to deliver good results. Many will have studied the team's attributes from afar but will have little to no first-hand experience of working at the club. There is a quick learning process as incoming coaches discern which management practices work best for their new employers. 
We note as a point for further research that our results do not entirely support the conjecture of a market for mediocre managerial talent advanced by Tervio (2009) and Peeters et al. (2016). If most coaches were mediocre then we would not observe any positive effects on team performance that we find from cases of fired coaches. It is possible that a Head Coach who appears mediocre at one club can be successful at another. Put another way, the value of a job match varies across clubs and each club has an idiosyncratic element in this value. A poorly performing club will tend to draw its hiring from the lower end of the ability distribution but such a coach can nevertheless help improve team performance.

Further work is needed to investigate heterogeneity of Head Coach effects on team performance, since coaches themselves are likely to be heterogeneous in ability (Peeters et al, 2016). Even if our estimates, and indeed estimates of past work, yield low or zero mean effects, there may well be some positive, some zero and some negative effects and it is worth probing into where and how these occur and of course whether there are systematic patterns to the positive and negative effects. Further work is also needed to evaluate estimates of Head Coach effects broken down by each league separately so as to establish any differences in effects of Head Coach firings across countries. 


\section{References}

Ashenfelter, O. (1978) "Estimating the Effect of Training Programs on Earnings", The Review of Economics and Statistics, 47-57

Bennedsen, M., Perez-Gonzalez, F. and Wolfenzon, D. (2012) "Evaluating the Impact of the Boss: Evidence from CEO Hospitalization Events", mimeo

Besley, T., Montalvo, J. G., and Reynal-Querol, M. (2011) "Do Educated Leaders Matter?", The Economic Journal, 121: F205-F227

Besters, L., Van Ours, J. and Van Tuijl, M. (2016). "Effectiveness of In-Season Manager Changes in English Premier League Football” Mimeo. Tilburg University

Bruinshoofd, A. and ter Weel, B. (2003). "Manager to go? Performance Dips Reconsidered with Evidence from Dutch Football", European Journal of Operational Research, 148: 233-246.

Bryson, A., Buraimo, B., Farnell, A. and Simmons, R. (2020) "Time to go? Head Coach Quits and Dismissals in Professional Football", De Economist https://link.springer.com/article/10.1007/s10645-020-09377-8

D’Addona, S. and Kind, A. (2014). "Forced Manager Turnovers in English Soccer Leagues", Journal of Sports Economics, 15, 2: 150-179.

De Grip, A. (2015) "The importance of informal learning at work ", IZA World of Labor 162

De Paola, M. and Scoppa, V. (2012) “The Effects of Managerial Turnover: Evidence from Coach Dismissals in Italian Soccer Teams", Journal of Sports Economics, 13, 2: $152-168$.

Dobson, S. and Goddard, J. (2011). The Economics of Football, $2^{\text {nd }}$ ed. Cambridge: Cambridge University Press

European Commission (2013) Labour Market Developments In Europe 2013, European Economy Series No. 6

Farber, H. S. (1999) "Mobility and Stability: The Dynamics of Job Change in Labor Markets", Chapter 37 in O. Ashenfelter and D. Card (eds.) Handbook of Labor Economics Volume 3, pp. 2439-2483

Ferguson, A. (2013) Alex Ferguson: My Autobiography, Hodder and Stoughton

Gaynor, M., Seider, H. and Vogt, W.B. (2005) "The Volume-Outcome Effect, Scale Economies, and Learning-by-Doing”, American Economic Review, 95, 2: 243-247 
Green, C., Lozano, F and Simmons, R. (2015) "Rank-Order Tournaments, Probability of Winning and Investing in Talent: Evidence from Champions' League Qualifying Rules", National Institute Economic Review, 232: R30-R40.

Hainmueller, J. (2012) "Entropy Balancing for Causal Effects: A Multivariate Reweighting Method to Produce Balanced Samples", Political Analysis, 25-46

Hainmueller, J. and $\mathrm{Xu}$, J. (2013) "ebalance: A Stata Package for Entropy Balancing", Journal of Statistical Software, 54, 7: 1-18

Lazear, E.P., Shaw, K.L. and Stanton, C.T. (2015) “The Value of Bosses”, Journal of Labour Economics, 33, 4, 823-861

Levitt, S. (2016) "Heads or Tails: The Impact of a Coin Toss on Major Life Decisions and Subsequent Happiness", NBER Working Paper \#22487

Madum, A. (2016) "Managerial Turnover and Subsequent Firm Performance: Evidence from Danish Soccer Teams", International Journal of Sport Finance, 11, 1: 46-62

Muehlheusser, G., Schneemann, S. and Sliwka, D. (2016) "The Impact of Managerial Change on Performance: The Role of Team Heterogeneity", Economic Inquiry, 54, 2: 1121-1149

Peeters, T., Szymanski, S. and Terviö, M. (2016) "Entry, Career Dynamics and Quality in the Labour Market for Talent", mimeo

Rosen, S. (1990) "Contracts and the Market for Executives", NBER Working Paper \#3542

Tena, J. D. and Forrest, D. (2007) "Within-Season Dismissal of Football Coaches: Statistical Analysis of Causes and Consequences", European Journal of Operational Research 181: $362-373$

Terviö, M. (2009) "Superstars and Mediocrities: Market Failure in the Discovery of Talent", The Review of Economic Studies, 76, 2: 829-850

Van Ours, J. C. and Van Tuijl, M. A. (2016) "In-season Head Coach Dismissals and the Performance of Professional Football Teams", Economic Inquiry, 54, 1: 591-60

Zhao, Q. and Percival, D. (2017) "Entropy Balancing is Doubly Robust”, Jounral of Causal Inference, 5,1 
APPENDIX

Table A1: Unweighted OLS Estimates (Dismissals)

\begin{tabular}{ccccccccccc} 
& \multicolumn{2}{c}{ no FE } & \multicolumn{2}{c}{ team FE } & season FE & N & Adj. R2 & & Team & Season \\
Mean Points Next ... Games & Coeff & s.e. & Coeff & s.e. & Coeff & s.e. & & No FE & FE & FE \\
\hline 1 & -0.007 & $(0.037)$ & 0.002 & $(0.038)$ & -0.007 & $(0.037)$ & 74,718 & 0.107 & 0.118 & 0.107 \\
2 & 0.035 & $(0.027)$ & 0.038 & $(0.027)$ & 0.035 & $(0.027)$ & 74,516 & 0.082 & 0.089 & 0.082 \\
3 & $0.040^{*}$ & $(0.022)$ & $0.036^{*}$ & $(0.022)$ & $0.040^{*}$ & $(0.022)$ & 74,311 & 0.110 & 0.118 & 0.110 \\
4 & 0.030 & $(0.019)$ & 0.023 & $(0.019)$ & 0.031 & $(0.019)$ & 74,106 & 0.121 & 0.134 & 0.122 \\
5 & 0.012 & $(0.017)$ & 0.001 & $(0.017)$ & 0.012 & $(0.017)$ & 73,901 & 0.141 & 0.159 & 0.141 \\
6 & 0.005 & $(0.016)$ & -0.008 & $(0.015)$ & 0.005 & $(0.016)$ & 73,697 & 0.154 & 0.179 & 0.155 \\
7 & -0.001 & $(0.015)$ & -0.016 & $(0.015)$ & -0.001 & $(0.015)$ & 73,493 & 0.170 & 0.200 & 0.170 \\
8 & 0.002 & $(0.014)$ & -0.014 & $(0.014)$ & 0.002 & $(0.014)$ & 73,286 & 0.183 & 0.219 & 0.183 \\
9 & -0.006 & $(0.014)$ & $-0.022^{*}$ & $(0.013)$ & -0.005 & $(0.014)$ & 73,078 & 0.196 & 0.238 & 0.196 \\
10 & 0.002 & $(0.013)$ & -0.015 & $(0.012)$ & 0.003 & $(0.013)$ & 72,869 & 0.208 & 0.256 & 0.208 \\
11 & 0.005 & $(0.012)$ & -0.013 & $(0.012)$ & 0.005 & $(0.012)$ & 72,661 & 0.218 & 0.272 & 0.219 \\
12 & 0.002 & $(0.012)$ & -0.018 & $(0.011)$ & 0.002 & $(0.012)$ & 72,454 & 0.228 & 0.287 & 0.229 \\
13 & 0.007 & $(0.012)$ & -0.012 & $(0.011)$ & 0.008 & $(0.012)$ & 72,246 & 0.237 & 0.301 & 0.238 \\
14 & 0.009 & $(0.011)$ & -0.011 & $(0.010)$ & 0.010 & $(0.011)$ & 72,039 & 0.245 & 0.314 & 0.245 \\
15 & 0.013 & $(0.012)$ & -0.008 & $(0.010)$ & 0.014 & $(0.012)$ & 71,831 & 0.251 & 0.326 & 0.251 \\
16 & 0.014 & $(0.011)$ & -0.007 & $(0.010)$ & 0.015 & $(0.011)$ & 71,624 & 0.257 & 0.337 & 0.257 \\
17 & 0.019 & $(0.011)$ & -0.004 & $(0.010)$ & $0.019^{*}$ & $(0.011)$ & 71,418 & 0.261 & 0.348 & 0.262 \\
18 & $0.020^{*}$ & $(0.011)$ & -0.003 & $(0.010)$ & $0.020^{*}$ & $(0.011)$ & 71,213 & 0.265 & 0.357 & 0.266 \\
19 & $0.026^{* *}$ & $(0.011)$ & 0.003 & $(0.010)$ & $0.026^{* *}$ & $(0.011)$ & 71,007 & 0.268 & 0.365 & 0.269 \\
20 & $0.026^{* *}$ & $(0.011)$ & 0.002 & $(0.010)$ & $0.026^{* *}$ & $(0.011)$ & 70,803 & 0.270 & 0.373 & 0.271 \\
\hline
\end{tabular}

Cluster Robust Standard Errors in Parentheses (clustered at the Team level) *p<0.1, **p $<0.05, * * * \mathrm{p}<0.01$ 
Table A2: Unweighted OLS Estimates (Quits)

\begin{tabular}{ccccccccccc} 
& \multicolumn{2}{c}{ no FE } & \multicolumn{2}{c}{ team FE } & season FE & N & \multicolumn{2}{c}{ Adj. R2 } & Team & Season \\
Mean Points Next ... Games & Coeff & s.e. & Coeff & s.e. & Coeff & s.e. & & No FE & FE & FE \\
\hline 1 & -0.058 & $(0.047)$ & $-0.077 *$ & $(0.046)$ & -0.059 & $(0.047)$ & 74,038 & 0.107 & 0.118 & 0.107 \\
2 & -0.045 & $(0.039)$ & -0.050 & $(0.039)$ & -0.046 & $(0.039)$ & 73,840 & 0.082 & 0.089 & 0.082 \\
3 & -0.025 & $(0.036)$ & -0.028 & $(0.036)$ & -0.026 & $(0.036)$ & 73,637 & 0.111 & 0.119 & 0.111 \\
4 & -0.022 & $(0.030)$ & -0.024 & $(0.030)$ & -0.023 & $(0.030)$ & 73,433 & 0.122 & 0.134 & 0.122 \\
5 & -0.020 & $(0.028)$ & -0.022 & $(0.027)$ & -0.021 & $(0.028)$ & 73,229 & 0.142 & 0.159 & 0.142 \\
6 & -0.003 & $(0.026)$ & -0.004 & $(0.026)$ & -0.004 & $(0.026)$ & 73,027 & 0.155 & 0.179 & 0.155 \\
7 & 0.004 & $(0.026)$ & 0.003 & $(0.025)$ & 0.003 & $(0.026)$ & 72,827 & 0.170 & 0.200 & 0.170 \\
8 & -0.001 & $(0.026)$ & -0.002 & $(0.026)$ & -0.001 & $(0.026)$ & 72,623 & 0.183 & 0.220 & 0.183 \\
9 & -0.001 & $(0.024)$ & -0.003 & $(0.024)$ & -0.002 & $(0.024)$ & 72,419 & 0.196 & 0.239 & 0.196 \\
10 & -0.010 & $(0.024)$ & -0.013 & $(0.023)$ & -0.011 & $(0.024)$ & 72,217 & 0.208 & 0.256 & 0.208 \\
11 & -0.013 & $(0.022)$ & -0.016 & $(0.021)$ & -0.014 & $(0.022)$ & 72,010 & 0.219 & 0.273 & 0.219 \\
12 & -0.003 & $(0.021)$ & -0.006 & $(0.020)$ & -0.004 & $(0.021)$ & 71,806 & 0.229 & 0.288 & 0.229 \\
13 & 0.002 & $(0.020)$ & -0.002 & $(0.019)$ & 0.001 & $(0.020)$ & 71,603 & 0.238 & 0.302 & 0.238 \\
14 & -0.000 & $(0.018)$ & -0.003 & $(0.018)$ & -0.001 & $(0.019)$ & 71,400 & 0.245 & 0.315 & 0.246 \\
15 & -0.006 & $(0.017)$ & -0.009 & $(0.017)$ & -0.007 & $(0.018)$ & 71,193 & 0.252 & 0.327 & 0.252 \\
16 & -0.005 & $(0.017)$ & -0.008 & $(0.016)$ & -0.005 & $(0.017)$ & 70,990 & 0.258 & 0.338 & 0.258 \\
17 & -0.009 & $(0.017)$ & -0.013 & $(0.016)$ & -0.010 & $(0.017)$ & 70,788 & 0.263 & 0.349 & 0.263 \\
18 & -0.009 & $(0.016)$ & -0.012 & $(0.015)$ & -0.010 & $(0.016)$ & 70,587 & 0.267 & 0.358 & 0.267 \\
19 & -0.013 & $(0.016)$ & -0.017 & $(0.015)$ & -0.014 & $(0.016)$ & 70,387 & 0.270 & 0.367 & 0.270 \\
20 & -0.013 & $(0.015)$ & -0.017 & $(0.014)$ & -0.013 & $(0.015)$ & 70,182 & 0.272 & 0.375 & 0.273 \\
\hline
\end{tabular}

Cluster Robust Standard Errors in Parentheses (clustered at the Team level) $* \mathrm{p}<0.1, * * \mathrm{p}<0.05, * * * \mathrm{p}<0.01$ 
Table A3: Multinomial Logistic Regression, Determinants of Exits

\begin{tabular}{|c|c|c|}
\hline VARIABLES & Dismissal & Quit \\
\hline \multicolumn{3}{|l|}{ Team Performance } \\
\hline Surprise t-1 & $\begin{array}{c}-0.312 * * * \\
(0.035)\end{array}$ & $\begin{array}{c}-0.123 * * \\
(0.051)\end{array}$ \\
\hline Surprise $\mathrm{t}-2$ to $\mathrm{t}-5$ & $\begin{array}{c}-0.155^{* * *} * \\
(0.024)\end{array}$ & $\begin{array}{c}-0.130 * * * \\
(0.036)\end{array}$ \\
\hline Surprise $\mathrm{t}-6$ to $\mathrm{t}-10$ & $\begin{array}{l}-0.024 \\
(0.024)\end{array}$ & $\begin{array}{l}-0.035 \\
(0.035)\end{array}$ \\
\hline Mean Points Prev 10 Games & $\begin{array}{c}-0.957 * * * \\
(0.189)\end{array}$ & $\begin{array}{l}-0.271 \\
(0.264)\end{array}$ \\
\hline Position & $\begin{array}{c}-0.031 * * * \\
(0.011)\end{array}$ & $\begin{array}{c}-0.048 * * * \\
(0.019)\end{array}$ \\
\hline Position Squared & $\begin{array}{c}0.001 * * \\
(0.000)\end{array}$ & $\begin{array}{c}0.001 * * * \\
(0.000)\end{array}$ \\
\hline Last Season Position & $\begin{array}{c}0.002 \\
(0.002)\end{array}$ & $\begin{array}{l}-0.000 \\
(0.003)\end{array}$ \\
\hline \multicolumn{3}{|l|}{ Coach Characteristics } \\
\hline Tenure & $\begin{array}{c}-0.002 * * \\
(0.001)\end{array}$ & $\begin{array}{c}0.006 * * * \\
(0.001)\end{array}$ \\
\hline Experience & $\begin{array}{c}-0.039 * * * \\
(0.008)\end{array}$ & $\begin{array}{c}-0.019 \\
(0.014)\end{array}$ \\
\hline Age & $\begin{array}{c}-0.007 \\
(0.057)\end{array}$ & $\begin{array}{c}-0.302 * * * \\
(0.087)\end{array}$ \\
\hline Age Squared & $\begin{array}{c}0.000 \\
(0.001)\end{array}$ & $\begin{array}{c}0.003 * * * \\
(0.001)\end{array}$ \\
\hline N Prev HC Jobs & $\begin{array}{c}0.050 * * * \\
(0.014)\end{array}$ & $\begin{array}{l}0.041^{*} \\
(0.022)\end{array}$ \\
\hline Internal Appointment & $\begin{array}{c}0.025 \\
(0.115)\end{array}$ & $\begin{array}{c}-0.428^{* *} \\
(0.198)\end{array}$ \\
\hline Previous Promotion & $\begin{array}{c}-0.265^{* * *} * \\
(0.076)\end{array}$ & $\begin{array}{c}0.048 \\
(0.122)\end{array}$ \\
\hline Previous Cup & $\begin{array}{c}-0.226^{* *} \\
(0.103)\end{array}$ & $\begin{array}{l}0.275^{*} \\
(0.143)\end{array}$ \\
\hline Previous Relegation & $\begin{array}{c}0.196 * * \\
(0.079)\end{array}$ & $\begin{array}{c}-0.266^{* *} \\
(0.134)\end{array}$ \\
\hline Ex Player & $\begin{array}{c}-0.218^{* *} \\
(0.109)\end{array}$ & $\begin{array}{c}-0.486 * * * \\
(0.181)\end{array}$ \\
\hline \multicolumn{3}{|l|}{ Season Progress } \\
\hline Proportion of Games Remaining & $\begin{array}{c}4.983 * * * \\
(0.652)\end{array}$ & $\begin{array}{l}-0.777 \\
(1.419)\end{array}$ \\
\hline Proportion of Games Remaining Squared & $\begin{array}{c}-5.059 * * * \\
(0.638)\end{array}$ & $\begin{array}{c}0.373 \\
(1.425)\end{array}$ \\
\hline Last Game of Season & $\begin{array}{c}4.638 * * * \\
(0.166)\end{array}$ & $\begin{array}{c}5.270 * * * \\
(0.299)\end{array}$ \\
\hline Observations & 66,157 & 66,157 \\
\hline
\end{tabular}

Standard errors in parentheses

$* * * \mathrm{p}<0.01, * * \mathrm{p}<0.05, * \mathrm{p}<0.1$ 
Table A4: Entropy Balancing (Dismissals)

Mean

Variance

Skewness

\begin{tabular}{|c|c|c|c|c|c|c|c|c|c|}
\hline & \multicolumn{3}{|c|}{ Mean } & \multicolumn{3}{|c|}{ Variance } & \multicolumn{3}{|c|}{ Skewness } \\
\hline & $\begin{array}{l}\text { Unweighted } \\
\text { Treatment } \\
\end{array}$ & $\begin{array}{l}\text { Unweighted } \\
\text { Control } \\
\end{array}$ & $\begin{array}{l}\text { Weighted } \\
\text { Control } \\
\end{array}$ & $\begin{array}{l}\text { Unweighted } \\
\text { Treatment } \\
\end{array}$ & $\begin{array}{l}\text { Unweighted } \\
\text { Control } \\
\end{array}$ & $\begin{array}{l}\text { Weighted } \\
\text { Control } \\
\end{array}$ & $\begin{array}{l}\text { Unweighted } \\
\text { Treatment } \\
\end{array}$ & $\begin{array}{l}\text { Unweighted } \\
\text { Control } \\
\end{array}$ & $\begin{array}{l}\text { Weighted } \\
\text { Control } \\
\end{array}$ \\
\hline Surprise $\mathrm{t}-1$ & -0.4482 & 0.02179 & -0.4481 & 1.076 & 1.438 & 1.075 & 0.9632 & 0.251 & 0.9632 \\
\hline Surprise $\mathrm{t}-2$ to $\mathrm{t}-5$ & -1.097 & 0.08274 & -1.097 & 4.764 & 5.618 & 4.763 & 0.4275 & 0.1144 & 0.4274 \\
\hline Surprise $\mathrm{t}-6$ to $\mathrm{t}-10$ & -0.7296 & 0.09391 & -0.7296 & 5.765 & 7.024 & 5.764 & 0.3676 & 0.09937 & 0.3675 \\
\hline Mean Points Prev 10 Games & 1.069 & 1.401 & 1.069 & 0.1722 & 0.228 & 0.1722 & 0.5912 & 0.2315 & 0.5919 \\
\hline Position & 17.1 & 19.99 & 17.09 & 162.7 & 156.6 & 162.7 & 0.2108 & 0.2828 & 0.2119 \\
\hline Position Squared & 454.8 & 556 & 454.8 & 238663 & 315283 & 238643 & 0.954 & 0.8982 & 0.9542 \\
\hline Last Season Position & 30.08 & 28.36 & 30.08 & 516.1 & 477.8 & 516.1 & 0.1102 & 0.2905 & 0.1105 \\
\hline Tenure & 38.85 & 44.61 & 38.85 & 1126 & 2225 & 1125 & 1.903 & 2.696 & 1.903 \\
\hline Experience & 11.46 & 11.47 & 11.45 & 63.38 & 59.25 & 63.37 & 0.7147 & 0.7602 & 0.7151 \\
\hline Age & 49.22 & 48.42 & 49.21 & 45.65 & 43.21 & 45.65 & 0.3663 & 0.3959 & 0.3677 \\
\hline Age Squared & 2468 & 2388 & 2468 & 468590 & 430630 & 468551 & 0.7298 & 0.754 & 0.731 \\
\hline N Prev HC Jobs & 4.877 & 4.385 & 4.876 & 17.82 & 15.06 & 17.82 & 1.16 & 1.283 & 1.16 \\
\hline Internal Appointment & 0.1367 & 0.1386 & 0.1369 & 0.1181 & 0.1194 & 0.1181 & 2.115 & 2.092 & 2.113 \\
\hline Previous Promotion & 0.4981 & 0.5254 & 0.4981 & 0.2502 & 0.2494 & 0.25 & 0.007648 & -0.1016 & 0.007628 \\
\hline Previous Cup & 0.1396 & 0.1959 & 0.1398 & 0.1202 & 0.1575 & 0.1202 & 2.08 & 1.532 & 2.078 \\
\hline Previous Relegation & 0.3184 & 0.2678 & 0.3186 & 0.2172 & 0.1961 & 0.2171 & 0.7799 & 1.049 & 0.7785 \\
\hline Ex Player & 0.1338 & 0.1604 & 0.134 & 0.116 & 0.1347 & 0.1161 & 2.151 & 1.851 & 2.149 \\
\hline Proportion of Games Remaining & 0.3355 & 0.489 & 0.3354 & 0.09008 & 0.07989 & 0.09007 & 0.2687 & 0.01582 & 0.2694 \\
\hline Proportion of Games Remaining Squared & 0.2025 & 0.319 & 0.2026 & 0.0559 & 0.08237 & 0.05589 & 1.044 & 0.6702 & 1.043 \\
\hline Last Game of Season & 0.3193 & 0.01488 & 0.3196 & 0.2176 & 0.01465 & 0.2175 & 0.7751 & 8.015 & 0.7738 \\
\hline
\end{tabular}


Table A5: Entropy Balancing (Quits)

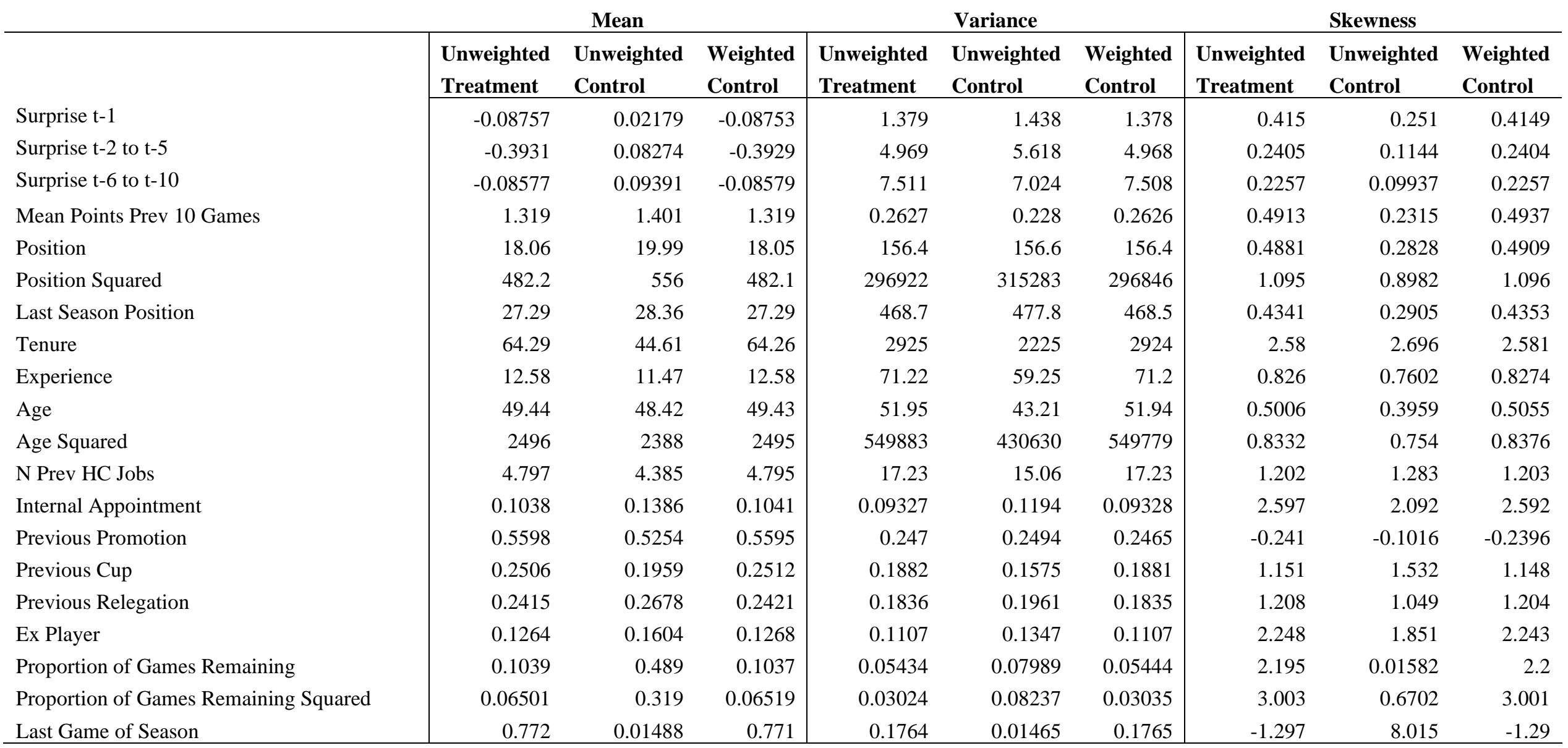


Table A6: Excluding Relegations

\begin{tabular}{|c|c|c|c|c|c|c|c|c|c|c|c|c|c|c|}
\hline \multirow[b]{2}{*}{$\begin{array}{l}\text { Mean Points } \\
\text { Next ... Games }\end{array}$} & \multicolumn{4}{|c|}{$\begin{array}{c}\text { Dismissals } \\
\text { team FE }\end{array}$} & \multirow[t]{2}{*}{$\mathbf{N}$} & \multicolumn{2}{|l|}{ Adj. R2 } & & FE & \multicolumn{4}{|c|}{ Quits } & \\
\hline & Coeff & s.e. & Coeff & s.e. & & No FE & $\begin{array}{l}\text { Team } \\
\text { FE }\end{array}$ & Coeff & s.e. & Coeff & & & No FE & $\begin{array}{l}\text { Team } \\
\text { FE }\end{array}$ \\
\hline 1 & -0.027 & $(0.048)$ & -0.003 & $(0.045)$ & 59,933 & 0.089 & 0.163 & 0.042 & $(0.072)$ & -0.005 & $(0.068)$ & 59,449 & 0.156 & 0.303 \\
\hline 2 & 0.036 & $(0.035)$ & 0.033 & (0.033) & 59,781 & 0.061 & 0.129 & 0.023 & $(0.054)$ & 0.009 & $(0.050)$ & 59,300 & 0.100 & 0.260 \\
\hline 3 & $0.049 *$ & $(0.029)$ & 0.039 & $(0.027)$ & 59,627 & 0.078 & 0.151 & 0.035 & $(0.046)$ & 0.016 & $(0.042)$ & 59,148 & 0.105 & 0.272 \\
\hline 4 & $0.045^{*}$ & $(0.026)$ & 0.034 & $(0.024)$ & 59,473 & 0.075 & 0.158 & 0.018 & $(0.041)$ & 0.008 & $(0.036)$ & 58,994 & 0.109 & 0.288 \\
\hline 5 & 0.019 & $(0.023)$ & 0.009 & $(0.021)$ & 59,318 & 0.091 & 0.177 & 0.015 & $(0.037)$ & -0.005 & $(0.033)$ & 58,840 & 0.117 & 0.298 \\
\hline 6 & 0.009 & $(0.022)$ & -0.000 & $(0.020)$ & 59,163 & 0.097 & 0.201 & 0.026 & $(0.034)$ & 0.008 & $(0.030)$ & 58,687 & 0.125 & 0.319 \\
\hline 7 & -0.005 & $(0.020)$ & -0.015 & $(0.018)$ & 59,009 & 0.109 & 0.218 & 0.023 & $(0.032)$ & 0.002 & $(0.028)$ & 58,535 & 0.136 & 0.342 \\
\hline 8 & -0.003 & (0.019) & -0.014 & $(0.017)$ & 58,853 & 0.112 & 0.232 & 0.017 & $(0.030)$ & -0.003 & $(0.026)$ & 58,380 & 0.149 & 0.379 \\
\hline 9 & -0.012 & (0.019) & -0.026 & $(0.017)$ & 58,696 & 0.119 & 0.249 & 0.010 & $(0.029)$ & -0.013 & $(0.025)$ & 58,227 & 0.149 & 0.384 \\
\hline 10 & 0.002 & $(0.018)$ & -0.014 & $(0.016)$ & 58,537 & 0.133 & 0.263 & 0.005 & $(0.028)$ & -0.020 & $(0.024)$ & 58,073 & 0.172 & 0.414 \\
\hline 11 & 0.001 & (0.017) & -0.012 & $(0.015)$ & 58,378 & 0.136 & 0.275 & -0.007 & $(0.027)$ & -0.032 & $(0.023)$ & 57,915 & 0.180 & 0.428 \\
\hline 12 & -0.004 & (0.017) & -0.016 & $(0.014)$ & 58,217 & 0.141 & 0.288 & -0.000 & $(0.026)$ & -0.025 & $(0.022)$ & 57,757 & 0.192 & 0.443 \\
\hline 13 & 0.005 & $(0.016)$ & -0.007 & (0.014) & 58,057 & 0.143 & 0.302 & 0.007 & $(0.025)$ & -0.019 & $(0.021)$ & 57,600 & 0.196 & 0.455 \\
\hline 14 & 0.008 & $(0.016)$ & -0.003 & $(0.014)$ & 57,896 & 0.153 & 0.316 & 0.007 & $(0.025)$ & -0.018 & $(0.021)$ & 57,443 & 0.214 & 0.473 \\
\hline 15 & 0.009 & $(0.016)$ & -0.002 & $(0.013)$ & 57,735 & 0.155 & 0.331 & -0.001 & $(0.024)$ & -0.021 & $(0.020)$ & 57,282 & 0.216 & 0.471 \\
\hline 16 & 0.012 & (0.0 & 0.001 & $(0.013)$ & 57,572 & 0.158 & 0.340 & -0.001 & $(0.024)$ & -0.022 & $(0.020)$ & 57,123 & 0.224 & 0.480 \\
\hline 17 & 0.017 & $(0.015)$ & 0.004 & $(0.013)$ & 57,411 & 0.162 & 0.345 & -0.006 & $(0.023)$ & -0.025 & $(0.019)$ & 56,964 & 0.228 & 0.491 \\
\hline 18 & 0.015 & $(0.015)$ & 0.001 & $(0.012)$ & 57,250 & 0.164 & 0.350 & -0.005 & $(0.023)$ & -0.017 & $(0.019)$ & 56,806 & 0.244 & 0.502 \\
\hline 19 & 0.020 & $(0.014)$ & 0.006 & $(0.012)$ & 57,087 & 0.166 & 0.359 & -0.008 & $(0.022)$ & -0.020 & $(0.019)$ & 56,649 & 0.247 & 0.511 \\
\hline 20 & 0.019 & $(0.014)$ & 0.004 & $(0.012)$ & 56,925 & 0.165 & 0.369 & -0.007 & $(0.022)$ & -0.020 & $(0.018)$ & 56,488 & 0.248 & 0.521 \\
\hline
\end{tabular}

Cluster Robust Standard Errors in Parentheses (clustered at the Team level) $* \mathrm{p}<0.1,{ }^{* *} \mathrm{p}<0.05, * * * \mathrm{p}<0.01$ 
Table A7: Excluding Promotions

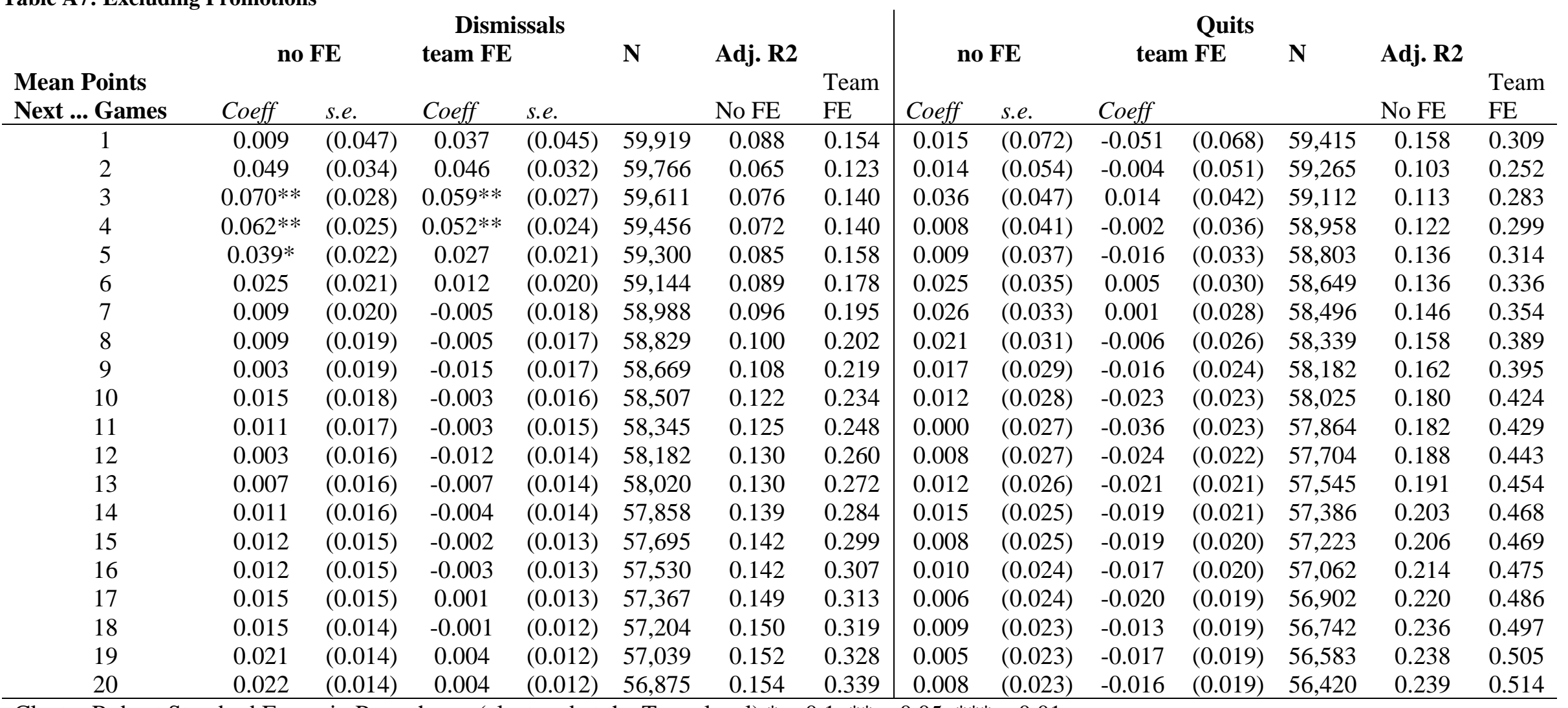

Cluster Robust Standard Errors in Parentheses (clustered at the Team level) $* p<0.1, * * p<0.05, * * * p<0.01$ 